\title{
The Development and Validation of a Multidimensional Measure of Moral Orientation
}

Erica A. Giammarco, The University of Western Ontario

Supervisor: Dr. Philip A Vernon, The University of Western Ontario

A thesis submitted in partial fulfillment of the requirements for the Master of Science degree in Psychology

(C) Erica A. Giammarco 2014

Follow this and additional works at: https://ir.lib.uwo.ca/etd

Part of the Personality and Social Contexts Commons

\section{Recommended Citation}

Giammarco, Erica A., "The Development and Validation of a Multidimensional Measure of Moral Orientation" (2014). Electronic Thesis and Dissertation Repository. 2255.

https://ir.lib.uwo.ca/etd/2255

This Dissertation/Thesis is brought to you for free and open access by Scholarship@Western. It has been accepted for inclusion in Electronic Thesis and Dissertation Repository by an authorized administrator of Scholarship@Western. For more information, please contact wlswadmin@uwo.ca. 
THE DEVELOPMENT AND VALIDATION OF A MULTIDIMENSIONAL MEASURE OF MORAL ORIENTATION

\author{
Erica A. Giammarco \\ Supervised by Dr. Philip A. Vernon \\ Graduate Program in Psychology \\ A thesis submitted in partial fulfillment \\ of the requirements for the degree of \\ Master of Science
}

The School of Graduate and Postdoctoral Studies

The University of Western Ontario

London, Ontario, Canada

(C) Erica Giammarco 2014 


\begin{abstract}
Researchers have found that when individuals are faced with moral dilemmas, they tend to approach the situations with the same general perspective. This general perspective is referred to as their moral orientation. Studies have shown that moral orientations tend to be either justice or care focused. A justice orientation refers to a focus on rights, rules, and objective decision making. In contrast, individuals using a care orientation are more likely to consider relationships, contextual factors, and minimizing harm to others. Although numerous studies have reported individual differences in these orientations, the literature has failed to consider how individuals with "abnormal" moral development approach these dilemmas. As such, the goal of present study was to develop a measure of moral orientation that was able to capture adequately the orientations of those individuals with more maladaptive tendencies. This was achieved by assessing a novel moral orientation, termed self-promotion. After developing and administering this scale to two independent samples, a series of item analyses were conducted and items that failed to meet acceptable levels of psychometric criteria were deleted. The reduced scaled was factor analyzed and the results indicated three distinct care, justice, and self-promotion factors emerged for some scenarios, but not others, suggesting that further scale revisions are necessary. Despite some potentially problematic items, preliminary validity evidence was found, with significant correlations in the expected direction observed between each of the moral orientation dimensions and various Dark Triad and HEXACO personality traits.
\end{abstract} Keywords: moral orientation, care, justice, antisocial personality 


\section{ACKNOWLEDGMENTS}

First and foremost, I would like to thank Dr. Tony Vernon for his continued guidance over the past few years. I am incredibly grateful for the many amazing opportunities he has afforded me, and appreciate the detailed feedback I received while working on this paper. I would also like to thank Dr. Sampo Paunonen, Dr. Richard Goffin, and Dr. Don Saklofske for their comments and suggestions throughout the development of this thesis. Also, thank you to Livia Veselka for her generous support throughout the writing process. Finally, thank you to my parents, family, and friends who have always supported and encouraged me. 


\section{TABLE OF CONTENTS}

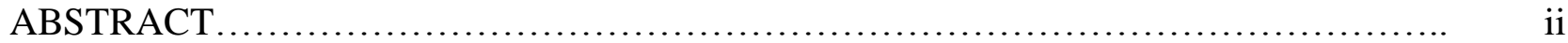

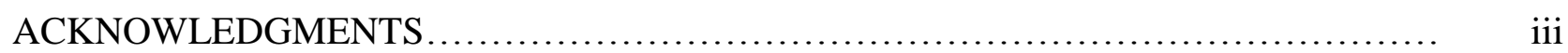

CHAPTER 1: INTRODUCTION AND LITERATURE REVIEW $\ldots \ldots \ldots \ldots \ldots \ldots \ldots \ldots \ldots \ldots . . \ldots \ldots$

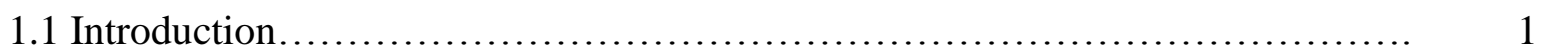

1.2 Kohlberg's Model of Moral Development.............................. 3

1.3 Gilligan and the Importance of Care .................................. 8

1.4 The Assessment of Moral Orientation.................................. 10

1.4.1 Dilemma Content.............................................. 11

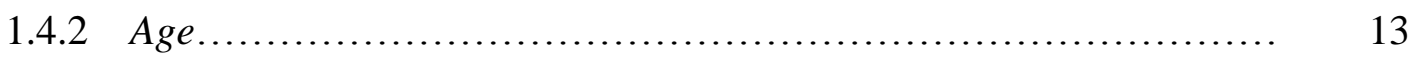

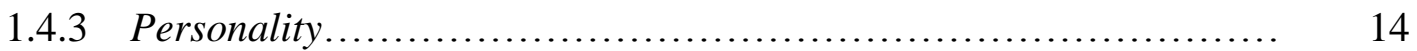

1.5 The Five Factor Model of Personality and Beyond...................... 15

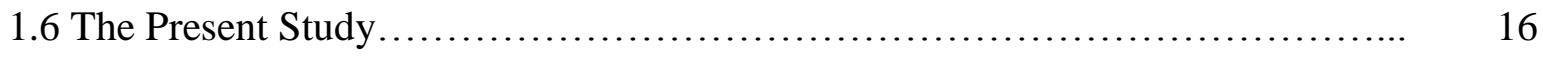

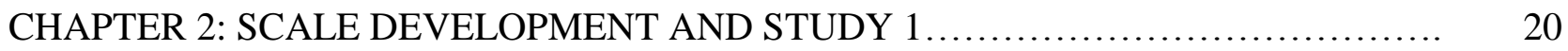

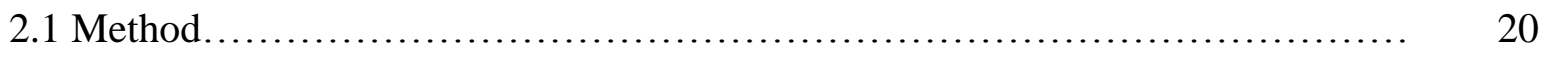

2.1.1 Participants............................................... 20

2.1.2 Materials and Procedures...................................... 20

2.1.3 Procedure.................................................... 23

2.2 Results.......................................................... 24

2.2.1 Careless Responders....................................... 24

2.2.2 Item Level Analyses........................................ 24

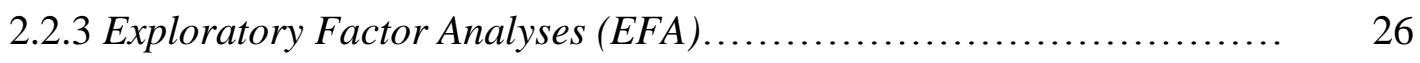

2.2.4 Analysis of Variance (ANOVA) on Instruction Set................... 29 


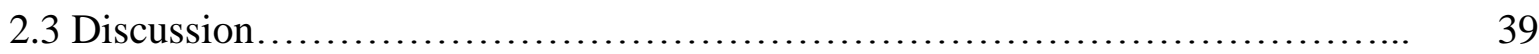

CHAPTER 3: STUDY 2 - ITEM REFINEMENT AND CONSTRUCT VALIDITY ........ 41

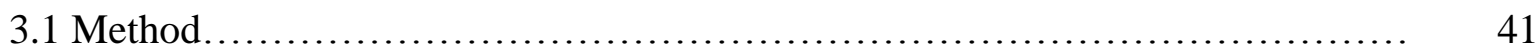

3.1.1 Participants.................................................... 41

3.1.2 Materials and Procedures........................................ 42

3.1.3 Procedure .......................................................... 43

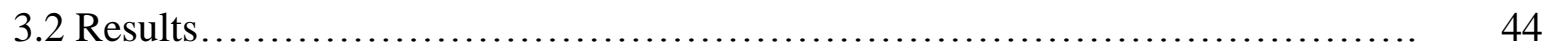

3.2.1 Careless Responders............................................... 44

3.2.2 Item Level Analyses............................................

3.2.3 Exploratory Factor Analyses....................................... 46

3.2.4 Sex Differences................................................ 54

3.2.5 Convergent and Construct Validity ................................. 54

3.3 Discussion.............................................................. 57

CHAPTER 4: GENERAL DISCUSSION AND CONCLUSIONS ....................... 58

4.1 General Discussion................................................... 58

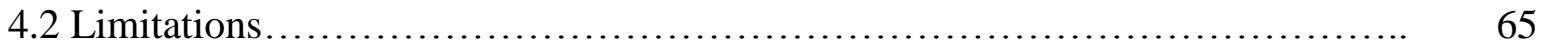

4.3 Future Directions.......................................................... 67

4.3.1 Scale Development.............................................. 67

4.3.2 Computer Adaptive Testing...................................... $\quad 68$

4.3.3 Moral Orientation in the Workplace ................................. $\quad 69$

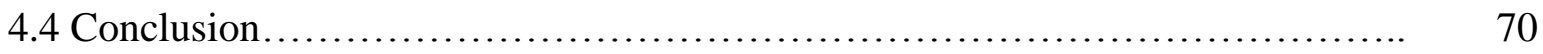

REFERENCES........................................................................ 71 
TABLE 1: Study 1 Zero-Order Correlations between the AMO and MMO-2 Care and

Justice Subscales.................................................... 27

TABLE 2: EFA Factor Loadings for MMO-2 by Scenario........................... 30

TABLE 3: EFA Factor Loadings for AMO Impersonal Version Scenario 1................ 33

TABLE 4: EFA Factor Loadings for AMO Impersonal Version Scenario 2................ 34

TABLE 5: EFA Factor Loadings for AMO Impersonal Version Scenario 3................ 35

TABLE 6: EFA Factor Loadings for AMO Impersonal Version Scenario 4................. 36

TABLE 7: EFA Factor Loadings for AMO Impersonal Version Scenario 5................ 37

TABLE 8: EFA Factor Loadings for AMO Impersonal Version Scenario 6............... 38

TABLE 9: Study 2 Descriptive Statistics......................................... 45

TABLE 10: Study 2 EFA Factor Loadings for Scenario $1 \ldots \ldots \ldots \ldots \ldots \ldots \ldots \ldots \ldots \ldots \ldots \ldots \ldots$

TABLE 11: Study 2 EFA Factor Loadings for Scenario $2 \ldots \ldots \ldots \ldots \ldots \ldots \ldots \ldots \ldots \ldots \ldots . \ldots \ldots$

TABLE 12: Study 2 EFA Factor Loadings for Scenario $3 \ldots \ldots \ldots \ldots \ldots \ldots \ldots \ldots \ldots \ldots \ldots \ldots . \ldots \ldots$

TABLE 13: Study 2 EFA Factor Loadings for Scenario 4........................... 51

TABLE 14: Study 2 EFA Factor Loadings for Scenario 5........................... 52

TABLE 15: Study 2 EFA Factor Loadings for Scenario $6 \ldots \ldots \ldots \ldots \ldots \ldots \ldots \ldots \ldots \ldots \ldots \ldots$

TABLE 16: Study 2 Zero-Order Correlations.................................... 55

APPENDIX A: Personal and Impersonal Versions of the AMO (Study 1)............... 84

APPENDIX B: NMREB Ethics Approval...................................... 96

APPENDIX C: Reduced Version of the AMO (Study 2).......................... 97

CURRICULUM VITAE........................................................ 101 


\section{CHAPTER ONE: INTRODUCTION AND LITERATURE REVIEW}

\subsection{Introduction}

Moral orientation refers to the general perspective an individual takes when approaching a moral dilemma. Researchers have found significant differences in the factors people consider when attempting to decide how they would behave in a dilemma (Haviv \& Leman, 2002;

Weinberg, Yacker, Orenstein, \& DeSarbo, 1993). In particular, some individuals tend to focus on contextual factors, such as recent hardships experienced by others. This is referred to as a care orientation and is characterized by a high regard for relationships and minimizing harm to others. In contrast, some individuals display a justice orientation, which is demonstrated by objectivity and rational thinking in decision making. These individuals are able to separate themselves from a situation and are more likely to focus on the rights, rules, and reciprocity in a scenario (Liddell, Halpin, \& Halpin, 1992).

A number of scales have been created to assess each of these orientations, including the Measure of Moral Orientation-2 (MMO-2; Liddell, 2006), the Moral Orientation Scale (MOS; Yacker \& Weinberg, 1990), and the Moral Justification Scale (MJS; Gump, Baker, \& Roll, 2000). However, these scales all suffer from the same limitation-normal moral development is an underlying assumption. In assuming normal moral development, these scales have failed to explain the moral orientations of those individuals with antisocial tendencies.

Personality research has experienced a shift in recent decades, which conceptualizes individual difference traits as existing on a continuum from normal to pathological, rather than being classified categorically (Haslam, 2011). In particular, research on maladaptive personality traits has focused on the so-called "Dark Triad". First proposed by Paulhus and Williams (2002), the Dark Triad consists of three distinct but related traits: Machiavellianism, narcissism, and 
psychopathy. Individuals high in Machiavellianism tend to be manipulative and deceitful (Christie \& Geis, 1970), while those high in psychopathy display impulsive behaviour and have little empathy for others (Hare, 1985). Lastly, narcissistic individuals think extremely highly of themselves, report grandiose self-views, and have strong feelings of entitlement (Raskin \& Hall, 1981).

Evidence that existing measures of morality do not capture adequately the behaviours of those with maladaptive tendencies was found by Bartles and Pizarro (2011). The researchers administered self-report measures of Machiavellianism and psychopathy, as well as the Defining Issues Test (DIT; Rest, Cooper, Coder, Masanz, \& Anderson, 1974). The DIT is a measure of moral reasoning, which presents participants with a number of hypothetical ethical dilemmas. Participants are asked how they would respond in the situation, and then they must rank the factors they consider to be most important in arriving at their decision.

Bartles and Pizarro found that individuals who reported psychopathic and Machiavellian traits tended to report a greater number of "optimal moral judgments": solutions that had the best outcome for the most number of people. This finding is clearly problematic for the construct validity of the DIT because individuals with psychopathic and manipulative tendencies, by definition, should not display optimal morality. In fact, Bartels and Pizarro concluded that such utilitarian responses had less to do with morality and more to do with a belief that life is meaningless. This may explain why non-empathetic individuals — as suggested by high psychopathy scores—-provided such answers.

Evidently, current conceptualizations of morality are problematic for populations with subclinical maladaptive tendencies. Although some researchers have shown that Machiavellianism and psychopathy are both positively associated with lower stages of moral 
reasoning, as would be expected, (Campbell et al., 2009) it is still unknown how these Dark Triad traits relate to moral orientation. It might be expected that those who score high on the Dark Triad would not display a care orientation, given that a lack of empathy is characteristic of these individuals. However, these individuals might not display a justice orientation either, because they tend to care less about reciprocity and equality, and more about self-gains.

As such, the purpose of the present study is to develop a measure of moral orientation that is able to capture adequately the orientation of those individuals with maladaptive tendencies. To assess moral orientation more comprehensively, a novel orientation will be developed in addition to existing orientations - one that is characterized by the tendency to focus on factors that directly impact oneself, regardless of the consequences to others. This new orientation has been termed self-promotion.

\subsection{Kohlberg's Model of Moral Development}

The study of morality has interested researchers for decades, yet a unified definition of the construct still does not exist. Some argue that morality refers to a universal code of ethics which applies to everyone and which all rational individuals abide by, whereas others suggest that morality is individualistic and describes a code of conduct accepted by an individual (Gert, 2011). Indeed it is possible to conceptualize how both definitions of morality could be true. For example, widespread taboos such as incest seem to suggest that there are certain behaviours that humans universally agree are morally wrong. However, the extensive controversy surrounding a number of issues including abortion and physician-assisted suicide points to individual differences in people's sense of what is and what is not moral.

One of the first researchers to empirically study moral development was Lawrence Kohlberg in the late 1950s. Kohlberg's (1958) model of moral development attempted to explain 
how normal morality develops across the lifespan. Kohlberg argued that all individuals progress through one or more of a series of six stages of moral development. Although not all individuals progress through all six stages, according to the theory, once a certain stage of development is reached, an individual cannot revert back to an earlier stage (Thoma, 1989).

As described by Crain (1985) Kohlberg proposed that moral development begins in childhood. The first and second stages are collectively referred to as the pre-conventional level. Both stages are characterized by making moral decisions based on the rules of one's society, and judging certain behaviours as right or wrong based on their physical consequences. More specifically, stage one is typically displayed in infancy and is solely focused on the physical consequences of behaviours and avoiding punishment. In contrast, in stage two the individual begins to understand that there are multiple sides to any issue and, as such, they choose to behave in ways that are personally beneficial. This stage is most commonly observed among preschool children.

Stages three and four make up the conventional level, and reflect the moral development of school-aged children. At this point in development, family expectations and national values begin to factor into decision-making as the individual reaches adolescence. Kohlberg suggested that the individual begins to accept social norms not simply to conform to society, but because of a sense of loyalty and support. In particular, individuals at stage three consider behaviour to be good or bad based on how others perceive it. As such, Kohlberg argues that individuals will try to conform to "good boy-nice girl" stereotypes. Progression to stage four is dominated by a law and order orientation. Doing the "right thing" is considered doing what is required to maintain social order. Respect for authority and performing one's "duty" are essential components of this stage of moral development. 
Lastly, stages five and six are labelled the post-conventional, autonomous, or principled levels. Here, individuals develop and define moral values that should be applied even when authority is not present. Stage five emphasizes individual rights and the democratic process, which gives everyone a voice in social order. Kohlberg argued that this stage is most common among teenagers. The final stage of moral development is not reached until adulthood, and focuses on universal human rights of equality and respect for everyone.

Kohlberg's seminal model was first tested in his dissertation study in 1958, which was not published until 1994. Kohlberg conducted a series of semi-structured interviews with young boys 10 to 16 years of age, employing what he referred to as the "Moral Judgments Scale" (MJS). During these interviews, participants were presented with a series of hypothetical moral dilemmas and asked how they would react in each situation. Once a child indicated their decision, the interviewer used a series of probes to investigate the child's justification for their responses. All responses were then coded against Kohlberg's six stages, and it was found that younger children received lower stage ratings than older children.

Unfortunately, attempts to replicate Kohlberg's findings were unsuccessful (Niemczynski, Czyzowska, Pourkos, \& Mirski, 1988). Due to the unstandardized nature of the MJS, researchers found little evidence of inter-rater reliability, construct validity, or stability in administration and question probes (Kurtines \& Grief, 1974; Turiel, 1966). The lack of basic psychometric properties severely limited the empirical investigation of Kohlberg's developmental model. Rest et al. (1974) attempted to address this concern by developing a standardized measure of Kohlberg's model of moral development: the Defining Issues Test (DIT). 
The DIT is a self-report measure of moral development that presents participants with a series of hypothetical moral dilemmas. Following each dilemma, the participant reads a number of statements that address relevant issues in the dilemma. The importance that individuals ascribe to each statement in their decision making process is rated on a five-point Likert scale. Each statement is written to reflect one of Kohlberg's stages. As such, if a participant rates an item as being highly important, the participant is assumed to be at the developmental stage exemplified by that item. An individual's moral development score is calculated by aggregating their endorsement of items across all dilemmas.

Preliminary validation studies of the DIT compared ratings of junior high school, senior high school, college, and graduate students (Rest et al., 1974). It was found that statements exemplifying higher stages of moral development were endorsed by more advanced students. In addition, participants' stage-ratings were consistent across situations.

Despite best attempts to produce a standardized measure of Kohlberg's stages, Rest et al.'s (1974) DIT suffers from a key design flaw. Initial validation studies found that children in grade nine and under experienced difficulty understanding the instructions of the DIT (Kay, 1982). As such, Rest, Davison, and Robbins (1978) admitted that the use of the DIT with children in elementary school would be inappropriate. As described by Kay (1982) in his comprehensive review of the literature on the DIT and Kohlberg's model, this is a major problem. That is, if a test designed to assess developmental stages is inappropriate for use on individuals at the earliest and most rapid-changing stages, this seriously compromises the utility of the measure.

In addition to this fundamental design flaw, Kay (1982) points to a series of methodological issues present in a number of early validation studies of the DIT. Arguably most 
important, cross-sectional validation studies of the DIT compared junior high, senior high, college, and graduate students' scores, concluding that higher stage scores among older participants was support for Kohlberg's developmental model. However, each of these studies failed to control for covariance between groups attributable to education, socio-economic status, and IQ. Failing to account for each of these additional variables confounds the conclusion that morality scores increase as a function of age. In fact, when DIT scores were compared against age and education, researchers found a positive association between moral judgements and education level, but a negative association with chronological age (Coder, 1975; Dortzbach, 1975, both as cited in Kay, 1982). These findings not only threaten the validity of the DIT, but they also challenge the developmental nature of Kohlberg's model.

Whereas Kohlberg's model of moral development was revolutionary and highly regarded at the time, it was clearly not without its critics. As previously mentioned, numerous early validation studies failed to control for variance in moral development scores that could be attributed to education and IQ (Martin, Shaftro, \& Van Deinse, 1977). Since these studies, researchers have found a significant association between moral development scores and IQ (Dawson, 2002; Taylor, 1978). In addition, not only do DIT scores increase as the number of years of education increase, but Coder (1975) found that scores increase more with special moral education programs than with non-moral education. Perhaps the most intriguing study looking at the association between DIT and education was conducted by Rest et al. (1978) who reported that when an individual discontinued formal education their moral development scores stabilized. Taken together, the results of these studies threaten the conclusion that higher DIT scores reflect a higher level of moral development. Rather, it may be that higher DIT scores are achieved because of greater IQ or abstract reasoning abilities. 
In addition to confounding cognitive abilities and education with moral development, researchers have criticized measures of Kohlberg's developmental model on the grounds that participants are rarely found to endorse stage five or six judgments (Kurtines \& Grief, 1974). When Kohlberg (1958) initially proposed his six-stage model, he speculated that the highest level of moral development would most typically be reached in late adolescence or early adulthood. However, researchers have found that not only is it is rare for young adults to display stage six judgements, but even those participants with advanced moral and theological training rarely report judgments indicative of this supposedly higher level of reasoning (Kurtines \& Grief, 1974). The relative rarity of post-conventional judgments, along with evidence that moral judgement measures are not suitable for use on young children severely challenges the existence, or at least the measurable existence, of six distinct stages of moral development.

Despite all these challenges, arguably the biggest criticism of Kohlberg's work came from his own student, Gilligan (1982). According to Gilligan, the fact that Kohlberg's (1958) sample consisted entirely of boys severely limited the generalizability of the model to girls. In fact, Gilligan proposed that the moral judgments made by girls were quite different from those of boys and as such, any measure of Kohlberg's stage model was inappropriate for use with female participants.

\subsection{Gilligan and the Importance of Care}

As mentioned by Gilligan (1982), psychology studies conducted prior to the 1970s predominately used male samples. In large part, this was due to the fact that there were more men than women at the institutions where this research took place. Consequently, as female enrolment in post-secondary schools increased, so did their inclusion in empirical studies. Unfortunately, as Gilligan describes, numerous developmental models were developed prior to 
this shift and as such, were based on predominately male samples. Kohlberg's (1958) stages of moral development was one such model.

When researchers administered Kohlberg-type moral dilemmas to females they found that young girls scored a full stage lower than their male counterparts, matched on IQ, socioeconomic status, and academic achievement (Holstein, 1972 as cited in Kurtines \& Grief, 1974). Examining participants' rational for their moral judgments, it became evident that females scored lower on these measures because they showed less sense of justice and greater concern for interpersonal relationships. As such, it appeared as though women's focus on relationships was impeding their moral development. Rather than concluding that women were less morally developed than men, Gilligan (1982) suggested that women's focus on relationships and nonviolent conflict resolution was not inferior to men's systematic and logical approach to moral dilemmas. Rather, the two approaches should be considered complementary, not sequential. Empirical investigations of sex differences on Kohlberg-type moral dilemmas, however, failed to provide consistent evidence of the male-bias that Gilligan (1982) proposed. Although some researchers did find that males scored higher on moral development measures than did females (Walker, 1984), numerous researchers failed to find any significant sex differences (Colby \& Damon, 1983; Lifton, 1985; Rest, 1979; Thoma, 1986). Complicating the issue further, some studies found that women actually scored higher than men on the DIT (Bruess \& Pearson, 2002). However, as mentioned by Jaffee and Hyde (2000), these studies did not test directly the assumption that males were more likely than females to use a justice orientation, as Gilligan proposed. In fact, because the Kohlberg-based scoring methods do not code typical 'care' responses, it is not possible to investigate properly the proposed hypothesis with these assessments. As such, researchers began to develop new scales to assess moral orientation. 


\subsection{The Assessment of Moral Orientation}

Gilligan's (1982) proposition that different forms of thought led to two distinct modes of moral judgment sparked a great deal of research on moral orientation. That is, rather than focusing on how morality develops, researchers became interested in studying the different ways people approached moral dilemmas, and in particular, if men and women display different orientations, on average.

A number of self-report measures of moral orientation were developed including the Measure of Moral Orientation (MMO; Liddell et al., 1992), MOS (Yacker \& Weinberg, 1990), and the MJS (Gump et al., 2000). Each of these scales contains a series of vignettes depicting different moral dilemmas. Following each vignette, participants are presented with a series of statements regarding different factors present in the dilemma, and are asked to rate their level of agreement with each statement using a Likert-scale rating system. Each statement is written to reflect either a care or a justice orientation. Liddell et al. (1992) defined a care orientation as displaying a focus on relationships and the feelings of others. Those individuals who use a care orientation make attempts to minimize harm done to others. In contrast, justice responses were operationalized as being rational and objective. Individuals endorsing these responses approach a given scenario as a third-party observer, and focus on the personal rights and legal ramifications of a dilemma.

Although the previous assessments of moral orientation all use a similar format, each offers a slightly unique way to assess moral orientation. The MMO (Liddell et al., 1992) was created for use with a university sample and its vignettes reflect dilemmas that a typical postsecondary student might encounter (e.g., a roommate plagiarizing their article for the student paper). In contrast, all the dilemmas used on the MOS (Yacker \& Weinberg, 1990) reflect 
childhood dilemmas (e.g., should you invite the unpopular child in your class to your birthday party). Lastly, the MJS (Gump et al., 2000) contains very long, detailed scenarios, and rather than having care and justice items for the same scenario, each scenario only contains either care or justice items.

With an assortment of tests available to assess care and justice responses, researchers once again investigated whether or not the gender differences suggested by Gilligan (1982) would be borne out in empirical studies using objective measures. Again, the results were mixed. A number of researchers did, in fact, find that women scored higher on care orientations, while men scored higher on justice (Donenberg \& Hoffman, 1988; Johnston, 1988; Liddell \& Davis, 1996; Yacker \& Weinberg, 1990). However, a number of studies found no significant sex differences in moral orientation (Beal, Garrod, Ruben, Stewart, \& Dekle, 1997; Friedman, Robinson, \& Friedman, 1987; Maqsud, 1998). These results led to a general agreement among most researchers that there are different types of moral orientations (namely, care and justice); however, it is greatly debated as to whether or not these differences are due to sex. As such, a number of alternative explanations have been proposed (Jaffee \& Hyde, 2000).

1.4.1 Dilemma content. With the increased attention being paid to moral orientation, a series of researchers argued that the content of the moral dilemmas presented to participants could have a large impact on the moral orientations used by these participants when solving the dilemmas (Rothbart, Hanley, \& Albert, 1986). Initially, it was suggested that perhaps the sex of the protagonist in the scenario could account for some variance in responses (Holstein, 1976). However, this was not found to have a significant impact on moral orientation (Garwood, Levine, \& Ewing, 1980). 
Next, concerns were raised as to whether or not people would respond consistently with the same orientation across scenarios. Bush, Krebs, and Carpendale (1993) found that participants responded very consistently across philosophical, Kohlberg-type dilemmas. However, additional studies suggested that participants were less consistent across real-life dilemmas (Bartek, Krebs, and Taylor, 1993). An example of a Kohlberg-type dilemma is whether you should push a large man onto a set of train tracks to stop an oncoming train from killing a group of children. In contrast, real-life dilemmas were generated by participants when they were asked to describe a recent moral dilemma from their personal lives. A study by Wark and Krebs (1997) reported that participants were consistent in their endorsement of either a care or justice moral orientation approximately $90 \%$ of the time in Kohlberg-type moral dilemmas, but only $68-75 \%$ consistent in real-life dilemmas.

Of course if the goal of an assessment tool is to be as psychometrically sound as possible, participants should be responding consistently across items. This would suggest that scales of moral orientation should rely exclusively on Kohlberg-type scenarios. However, the utility of such an assessment would be severely limited if it did not reflect how individuals actually thought about moral dilemmas in real life. As such, it may be that such scenario-based assessments need to sacrifice some psychometric properties in order to enhance their external validity.

Further evidence that dilemma content can impact moral orientation responses was reported in a series of studies by Wark and Krebs (1997; 2000). Participants responded to prosocial and antisocial dilemmas. Prosocial dilemmas were defined as those that required participants to decide whether they should help someone or decide how to respond when two friends were placing inconsistent demands on them. In contrast, antisocial dilemmas were 
labelled as those that involved behaving dishonestly and/or breaking the law/rules. It was found that prosocial dilemmas evoked more care responses, although this effect was weak. Also, antisocial dilemmas tended to evoke more justice responses. Additional researchers have found similar results (Crandall, Tsang, Goldman, \& Pennington, 1999; Haviv \& Leman, 2002).

From these studies, it is clear that the content of the dilemma is important to consider when assessing moral orientation. It could be argued that dilemmas written as either prosocial or antisocial, as described by Wark and Krebs (1997), would lend themselves to certain orientations because the dilemmas contain more opportunities for one type of response versus another (i.e., laws and consequences are salient in antisocial dilemmas but not in prosocial, causing people to tend to use a justice orientation). As such, it seems that the ideal scenario would contain elements of both prosocial and antisocial content, so as not to influence responses too strongly. As a caveat, it should also be noted that, although it was found that certain dilemmas favoured one orientation more than another, both orientations were found across both dilemmas. This indicates that although the dilemma has an effect, there is additional variance in moral orientation scores that can be accounted for by other variables.

1.4.2 Age. Early researchers suspected that age may have an impact on moral orientation given that sex differences were found to exist in adult samples, but not among children (Walker, de Vries, \& Trevethan, 1987). Pratt, Golding, Hunter, and Sampson (1988) found significant sex differences in an adult sample, but only for those individuals in middle adulthood (as compared to younger and older adults). More recent studies suggest there is no correlation between moral orientation and age (Glover, 2001). The limited number of studies on this topic and the lack of consistent findings suggest that further research is needed to determine the extent of any relations between age and moral orientation. Research focusing on young children found that the use of 
care orientations increased for children 6 to 8 years of age, at the same time that the use of justice orientations decreased for both boys and girls (Muthukrishna \& Govender, 2011). These results confirm the notion that research conducted with adult samples should not be assumed to extrapolate to children. In addition, the seemingly unstable nature of moral orientations suggests that assessments used on adults may not be suitable for children.

1.4.3 Personality. A number of researchers have investigated associations between personality and moral reasoning (Glenn, Koleva, Iyer, Graham, \& Ditto, 2010; Koenigs, Kruepke, Zeier, \& Newman, 2012). These investigations have predominately focused on the role of psychopathy in moral decision making. Using both student (Gao \& Teng, 2013) and incarcerated (Koenigs et al., 2012) samples it was found that utilitarian judgments were more common among individuals who scored high on self-reported measures of psychopathy. These findings support the results of Bartels and Pizzaro (2011) discussed above.

Unfortunately, surprisingly little research has examined the association between personality and moral orientation, specifically. A study conducted by Glover (2001) examined relations between the MOS and the Myers-Briggs Type Indicator (MBTI, Myers \& McCaulley, 1985). It was found that care and justice orientations were less related to gender roles and more strongly associated with personality types. In particular, a justice orientation was positively correlated with judging and intuition personality traits, whereas a care orientation was associated with perceiving and sensing traits. In addition, justice was found to be correlated with extraversion, and care with introversion. These results were later replicated in an independent study (Anwar, Bhutto, Maitlo, \& Khawaja, 2012).

It should be noted that a number of researchers have criticized the use of the MBTI for individual differences research (Comrey, 1983; Pittenger, 1993; Vacha-Haase \& Thompson, 
2002). In particular, McCrae and Costa (1989) argue that the MBTI does not adequately measure distinct personality types, but instead could be conceptualized as measuring four of the five relatively independent personality dimensions outlined by the Five Factor Model (FFM; Costa \& McCrae, 1992. Re-interpreting the MBTI in this way would make it an inappropriate assessment of Jungian-theory, as was initially intended.

\subsection{The Five Factor Model of Personality and Beyond}

For decades the FFM has dominated individual differences research, with an overwhelming body of literature supporting its existence (McCrae \& Costa, 1997; Ones \& Viswesvaran, 1996; Saucier \& Goldberg, 1998). The FFM proposes that there are five distinct dimensions of personality which can account for all individual differences in personality. These dimensions are Agreeableness (helpful, good-natured, cooperative, friendly), Conscientiousness (self-disciplined, dutiful, organized, preference for planning), Extraversion (outgoing, energetic, assertive, sociable), Neuroticism (tendency to experience negative emotions such as anxiety, anger, depression), and Openness to Experience (appreciation for beauty, creativity, adventure, curiosity).

In addition to the FFM, the six-factor HEXACO (Lee \& Ashton, 2004) model has gained considerable research attention (Gaughan, Miller, \& Lynam, 2012; Jonason \& McCain, 2012; Lee \& Ashton, 2014). Five of the six personality traits described by the HEXACO model (Agreeableness, Conscientiousness, Extraversion, Openness, and Emotionality) are similar to the FFM dimensions described previously. The major difference between HEXACO and the FFM is the inclusion of the Honesty-Humility factor. Individuals who score high on Honesty-Humility tend to follow the rules, avoid manipulating others for personal gain, and do not feel a sense of 
entitlement. As such, it could be argued that HEXACO assesses a broader range of personality traits, and therefore is more desirable for individual differences research.

Although the HEXACO and FFM have greatly advanced our understanding of normative personality traits, they have also been the subject of much criticism in recent years (Paunonen \& Jackson, 2000). In particular, researchers have argued that the FFM is not able to capture adequately the full range of personality traits, especially those that reflect socially malevolent behaviours (Veselka, Schermer, \& Vernon, 2012). For this reason, alternative models, such as the Dark Triad, have been proposed.

The inclusion of maladaptive personality traits when investigating morality is of particular importance if we wish to study the full range of morality. Although various measures of moral orientation currently exist (Gump et al., 2000; Liddell, 2006; Yacker \& Weinberg, 1990) each scale suffers from the same limitation - normal moral development is an underlying assumption. There is currently no known self-report assessment of moral orientation that specifically assesses how individuals with presumable deficits in morality would respond to ethical dilemmas. As such, it seems as if the existing conceptualization of moral orientation may contain one of the same limitations as the FFM - it only capture the responses of those that fall within the domain of "normal" personality.

\subsection{The Present Study}

Current conceptualizations of morality have largely overlooked those populations with subclinical maladaptive tendencies. Those few studies that have examined morality within these samples have produced results that are problematic for the construct validity of current assessment tools. With respect to moral orientation, it is unclear whether current measures would 
assess adequately the moral judgments of those with antisocial tendencies, or if alternative assessments would be better suited for use with these populations.

As such, the purpose of the present study is to develop a measure of moral orientation that is able to capture adequately the orientations of those individuals with maladaptive tendencies. This goal will hopefully be achieved by assessing a novel moral orientation, characterized by the tendency to focus on factors that directly impact oneself, regardless of the consequences to others. Such an orientation would diverge from a care orientation because consequences to others are not considered, and it would also differ from a justice orientation in that the focus is on the consequences to oneself, not on what is just or fair. This new orientation will be referred to as self-promotion. Given the extensive literature linking the Dark Triad traits to empathy deficits, inflated self-views, and a disregard for other's well-being (Paulhus \& Williams, 2002), it is reasonable to expect that individuals with these tendencies would be likely to attend to factors that impact themselves, rather than others, in moral dilemmas.

This thesis consists of two studies. In Study 1, the novel moral orientation measure, termed the Assessment of Moral Orientation (AMO) was developed and administered to a sample of undergraduate university students, along with an existing measure of moral orientation and a social desirability inventory. The purpose of this study will be to examine the effect of scenario content on moral orientation. Participants in Study 1 will all receive the same moral dilemmas, but they will be randomly selected to receive the scenarios in either a personal or an impersonal context. It is expected that participants will respond more objectively in impersonal situations (reflecting a justice orientation), but that care orientations will be more prevalent among personal scenarios. Preliminary item analyses will also be conducted and any items that correlate highly with social desirability indices will be considered for deletion. 
Based on the results of Study 1, the AMO will be modified and administered to a large community sample in Study 2. Participants in this second study will also complete an existing moral orientation measure as a validity criterion, the MMO-2, as well as measures of the Dark Triad and HEXACO personality traits. The MMO-2 was selected over other moral orientation measures because it seemed to be the best fit for the adult sample. After completing a series of item analyses on the proposed scale, those items which fail to meet certain psychometric criteria will be removed from future analyses. The remaining items will be factor analyzed, with three factors reflecting care, justice, and self-promotion expected.

Associations between the proposed scale and an existing measure of moral orientation will be examined for evidence of convergent validity for the care and justice scales. Study 2 will also attempt to provide validation evidence for the proposed scale by examining its association with the Dark Triad and HEXACO. In particular, care orientations scores are expected to be negatively correlated with each of the Dark Triad traits. Given that previous research has found psychopathy to be the "darkest" of the Dark Triad traits (Jonason \& Krause, 2013), it is expected that psychopathy will demonstrate the strongest negative association with care. Also, selfpromotion scores are expected to be significantly positively correlated with Machiavellianism, narcissism, and psychopathy.

With respect to HEXACO, Honesty-Humility and Conscientiousness are both expected to be negatively associated with a self-promotion moral orientation. These associations are expected due to the research indicating low scores on Honesty-Humility reflect a tendency to be manipulative for personal gain, and low scores on Conscientiousness are associated with impulsivity and a lack of concern for ones surroundings (Lee \& Ashton, 2014). For these reasons, Honesty-Humility and Conscientiousness are also expected to be positively associated 
with justice. Care is expected to be positively correlated with Agreeableness give that both constructs reflect a concern for maintaining relationships and care is also expected to be positively correlated with Emotionality because those who score high on Emotionality tend to seek attachment and emotional support from others (Lee \& Ashton, 2014). 


\section{CHAPTER TWO: SCALE DEVELOPMENT AND STUDY 1}

As discussed in Chapter 1, previous researchers have found that dilemma content can have an impact on self-reported moral orientation ratings (Wark \& Krebs, 2000). As such, it was expected that an individual's approach to moral dilemmas may differ depending on how personal the situation is deemed to be. In particular, it could be reasonably argued that individuals would be more likely to make objective and rational decisions (justice orientation) when the situation involves other people (impersonal), but they may consider relationships and contextual factors more (care) when they are actually in the situation themselves (personal). As such, Study 1 was conducted to determine if varying questionnaire instructions and scenario wording would influence moral orientation ratings.

\subsection{Method}

\subsubsection{Participants}

The sample consisted of 200 undergraduate students (69 male, 131 female) recruited from an introductory psychology course at a large Ontario university. Participants ranged in age from 17 to 25 years $(M=18.79, S D=1.431$ years $)$ and received partial credit in exchange for their participation. The study was administered online via FluidSurvey and took approximately 30 minutes to complete.

\subsubsection{Materials and Procedures}

Assessment of Moral Orientation (AMO). The AMO was developed for the present study to assess moral orientation in individuals with a range of antisocial tendencies (from normal to subclinical). The scale was constructed to measure three facets, each reflecting a unique orientation: care ("I would not want to hurt my partner."), justice ("I would feel uncomfortable violating school policy."), and self-promotion ("I could use this opportunity to 
boost my average for graduation.”). Orientations were first operationally defined based on previous assessments of the constructs (see Chapter 1; Liddell et al., 1992). Next, hypothetical scenarios reflecting real-life moral dilemmas were generated. North American online opinion polls were screened and issues that were not overtly religiously or politically charged were selected for scenario content (Moral Issues, 2013).

Six scenarios were written and administered to a group of graduate students who rated each scenario according to Moral Foundations Theory (MFT; Graham et al., in press). This theory states that there are five moral themes that are present across cultures: care/harm, fairness/cheating, loyalty/betrayal, authority/subversion, and sanctity/degradation. Scenarios for the AMO were rated by psychology graduate students on each of these five themes to ensure a broad range of moral dilemmas were covered. Analysis of the ratings showed that all raters agreed that each of the moral foundations was present in at least one of the scenarios, with the exception of sanctity/degradation. This moral foundation was reported present in one scenario by three of the five raters. Given that the definition of this foundation contained an example that was actually the theme of this scenario (physician assisted suicide) this was taken as an acceptable level of agreement.

Thirty-one preliminary response items were written and presented to a focus group of four psychology graduate students. Each item was written to reflect a care, justice, or selfpromotion factor specific to one scenario. Discussion pertaining to the items revealed concerns that the item content for the self-promotion factor was too extreme in nature and would lead to socially desirable responding and low variability in responses. These concerns were taken into consideration and a second item pool was generated. This second item pool contained six scenarios written in the personal context (i.e., imagine yourself in the situation), and six identical 
scenarios written in the impersonal context (i.e., Joe Smith is in the situation). There were a total of 113 response items across all 12 scenarios (57 items for the personal scenarios, 56 for the impersonal). This second draft was examined by two experts in personality and measurement. Concerns about item homogeneity and scenario length were expressed.

Following these comments, the scenarios were revised to lower the overall reading level to grade seven, with a total of 74 items per condition (i.e., personal versus impersonal). The instruction set was also revised to include three conditions: personal (i.e., what would you do), somewhat personal (i.e., if you were Joe, what would you do), and impersonal (i.e., what do you think Joe would do). In addition, one item for each scenario was added to check for careless responding. These items make up the reading check scale. This scale does not have an impact on participants' scores on the care, justice, or self promotion scales. Rather, the items were designed to test if participants have read the scenario carefully. All items were measured on a 5-point Likert scale, with higher scores reflecting a greater endorsement of the orientation $(1=$ extremely unlikely, 5 = extremely likely; see Appendix A for personal and impersonal versions of the AMO).

Measure of Moral Orientation-2 (MMO-2). Developed by Liddell (2006) the MMO-2 is a self-report measure that assesses the extent to which individuals approach moral situations using a care or a justice orientation. The MMO-2 contains seven dilemmas and 52 response items, each of which exemplifies either a justice ("Regardless of the consequences to my roommate, the article was mine and I have a right to have it published.") or care ("I would not do anything to harm my friendship with my roommate.”) orientation. Responses are measured on a 4-point Likert scale (1 = Strongly Disagree, 4 = Strongly Agree $)$. Liddell (2006) reported a Cronbach's alpha of .89 for the justice scale and .90 for the care scale. 
Balanced Inventory of Desirable Responding (BIDR-6).The BIDR-6 (Paulhus, 1991) is a self-report measure of social desirability which asks participants to indicate the veracity of a series of statements to assess whether or not individuals are responding truthfully. It consists of 40-items, rated on a 7 -point Likert scale $(1=$ not true, $7=$ very true $)$. The BIDR-6 measures two subscales, Self-Deceptive Enhancement (SDE; “I am a completely rational person.”) and Impression Management (IM; “Once in a while I laugh at a dirty joke.”). Cronbach's reliability alphas of .67 to .77 have been reported for the Self-Deceptive Enhancement subscale, and .77 to .85 for the Impression Management subscale (Paulhus, 1991).

\subsubsection{Procedure}

This study was approved by the University of Western Ontario Research Ethics Board for Non-Medical Research Involving Human Subjects (see Appendix B). Participants indicated their interest in the present study by signing up through the university's online research pool. After indicating interest in the study, participants received a link, which randomly directed them to one of three study URLs. Each URL first presented participants with the letter of information, which stated that their completion of the questionnaires was indication of their consent to participate. Next, participants completed the AMO, MMO-2, and BIDR-6. After completing all questionnaires, participants were debriefed.

Each URL contained unique instructions for the completion of the AMO. Those participants exposed to condition A received the instructions: "For each factor, please rate how likely it is to impact your final decision". Participants in condition B were told: "For each factor, please rate how likely you think it is to impact Kelly's final decision”, while those in condition C were told: "For each factor, please rate how likely it is to impact your final decision, if you were Kelly". As such, condition A contained personal scenarios with personal instructions, condition 
B contained impersonal scenarios with impersonal instructions, and condition $\mathrm{C}$ contained impersonal scenarios with semi-personal instructions.

\subsection{Results}

\subsubsection{Careless Responders}

A number of statistical procedures were performed to test for careless responders. First, participants who responded "agree" or "strongly agree" to any reading check items (e.g., "My grandmother's current treatment could cure her cancer" for the Assisted Suicide scenario) were removed from the sample, as endorsement of these reading check items was taken as an indication of inattentive responding.

Following the recommendations of Meade and Craig (2012) and Johnson (2005), a series of long string scores were computed for each participant. A long string score is computed by finding the number of consecutive items to which a participant consistently responds with the same answer (e.g., "4 strongly agree”). A long string score was computed for each response option for each participant. The mean long string score was then calculated, and any participants with a long string score one-half a standard deviation higher than this mean were removed from further analyses.

Next, the Mahalanobis distance among participants' response profiles was computed to test for outliers. This is a multivariate approach similar to Euclidian distance, but which also takes into account the covariance of data. Following these tests the sample was reduced from 227 to 200 participants.

\subsubsection{Item Level Analyses}

Preliminary analysis of the data assessed the means and standard deviations of the AMO items. Response items with a small standard deviation $(S D<1.0)$ were flagged for potential 
deletion given that low variability may suggest an item reflects an attitude that is either very uncommon, or likely to be endorsed by everyone (Jackson, 1970). However, items on the reading check scale were not flagged, because it is expected that all participants will score low on these items. In total, 17 items from condition A, 20 items from condition B, and 26 items from condition $\mathrm{C}$ were flagged for potential deletion due to low variability.

Next, item-total correlations were computed between each item and its hypothesized scale. Because correlating an item with a scale score that includes the item can inflate item-total correlations, scale scores were computed after removing the item of interest (Henrysson, 1963). Any item with a corrected item-total correlation smaller than .20 was considered for deletion (Dozois, Dobson, \& Ahnberg, 1998). A total of 23 items from condition A, 27 from condition B, and 20 from condition $\mathrm{C}$ failed to reach acceptable levels for corrected item-total correlations.

To test for internal consistency reliability, Cronbach's alphas were computed for the proposed care, justice, and self-promotion scales prior to any item deletion. For the care subscales the alpha values were $.59, .67$, and .63 for conditions A, B, and C respectively. For justice, internal consistency coefficients of .74, .67, and .77 were calculated for conditions A, B, and $\mathrm{C}$ respectively. Lastly, for self-promotion, the alpha values were $.73, .60$, and .78 respectively. Although some of these internal consistency estimates met the criteria for acceptable levels (Kline, 2000), they were likely inflated due to the large number of items in each scale. Because of this inflation, a stricter criterion for internal consistency is preferable. Consequently, the poor reliability is likely due to a number of low item-total correlations and suggests several items should be revised or removed from the scale.

In an attempt to control for social desirability, response items that correlated highly $(r>$ .20) with the BIDR-6 were considered for deletion or revision. In condition A 10 items 
correlated highly with IM, 9 with SDE, and 2 items with both BIDR-6 subscales. In condition B, 2 items correlated highly with IM, 2 with SDE, and 3 with both. Finally, in condition C, 9 items correlated with IM, 7 with SDE, and 2 with both.

Correlations between the AMO and MMO-2 care and justice scales were also computed to test for preliminary evidence of convergent validity. These results are reported in Table 1. For conditions A, B, and C, AMO care was significantly positively correlated with MMO-2 care. Similarly, AMO and MMO-2 justice scores were significantly correlated across all three conditions. Consistent with previous research (Liddell, 2006), the care and justice subscales of the MMO-2 were also significantly correlated with each other across all three conditions. However, care and justice scores on the AMO were not significantly correlated with each other in condition A, although they were in conditions B and C.

\subsubsection{Exploratory Factor Analyses (EFA)}

A series of EFAs were conducted to examine the structure of the 68 item AMO, separately for each condition. Because the six reading check items were added to assess for careless responding, they were not included in the factor analyses. Given that conditions B and C ( $N=69$, and $N=58$, respectively) contained the exact same scenarios and item wording, these samples were combined to allow for a large enough sample size to conduct the EFA. However, the sample size for condition $\mathrm{A}(N=73)$ was somewhat smaller than recommended by most researchers (Kline, 1979).

The EFAs were conducted using principal axis factoring (PAF), as recommended by Fabrigar, Wegener, MacCallum, and Strahan (1999). Because the subscales were expected to correlate with one another, an oblique rotation was selected. Fabrigar et al. (1999) advise against traditional factor extraction methods (e.g.., Kaiser criterion) when using PAF and instead 
Table 1

Study 1 Zero-Order Correlations between the AMO and MMO-2 Care and Justice Subscales

\begin{tabular}{|c|c|c|c|c|}
\hline & AMO Care & AMO Justice & MMO-2 Care & MMO-2 Justice \\
\hline \multicolumn{5}{|l|}{ Condition A } \\
\hline AMO Care & & .08 & $.58^{* * *}$ & $.22^{+}$ \\
\hline AMO Justice & & & .20 & $.48^{* * *}$ \\
\hline MMO-2 Care & & & & $.36^{* * *}$ \\
\hline \multicolumn{5}{|l|}{ MMO-2 Justice } \\
\hline \multicolumn{5}{|l|}{ Condition B } \\
\hline AMO Care & & $.42^{* * *}$ & $.70^{* * *}$ & $.50^{* * *}$ \\
\hline AMO Justice & & & $.44^{* * *}$ & $.44^{* * *}$ \\
\hline MMO-2 Care & & & & $.51^{* * *}$ \\
\hline \multicolumn{5}{|l|}{ MMO-2 Justice } \\
\hline \multicolumn{5}{|l|}{ Condition C } \\
\hline AMO Care & & $.29^{*}$ & $.61^{* * *}$ & $.45^{* * *}$ \\
\hline AMO Justice & & & $.33^{*}$ & $.60^{* * *}$ \\
\hline MMO-2 Care & & & & $.40^{* * *}$ \\
\hline MMO-2 Justice & & & & \\
\hline
\end{tabular}

Note. AMO refers to the Assessment of Moral Orientation and $\mathrm{MMO}-2$ to the Measure of Moral Orientation

*indicates significance at $p<.05$

$* *$ indicates significance at $p<.001$

tindicates a relation that failed to reach significance, but came close $p<.07$ 
recommend alternative tests. One such test recommended by O'Connor (2000) is the parallel analysis test. Parallel analysis compares the eigenvalues from the observed data to eigenvalues from simulated random data. The number of observed eigenvalues that are larger than the randomly generated eigenvalues reflects the number of factors that should be extracted. Following the recommendations of Fabrigar et al. (1999) and O'Connor (2000), the parallel analysis test was conducted to determine the number of factors that should be extracted for all EFA's performed in this study.

Unfortunately, an EFA could not be conducted for condition A because the limited sample size resulted in an error message when attempting to run both the parallel analysis test and the EFA. For the combined samples of conditions B and C parallel analysis suggested that seven factors be extracted. An EFA using PAF was conducted with an oblique rotation and seven factors extracted. The seven factors were found to account for $42.70 \%$ of the total variance in the model. Analysis of the factor loadings revealed that items from the same scenario tended to load onto the same factor. ${ }^{1}$

Because the scenario format of the AMO was modelled after the existing MMO-2 (Liddell, 2006) an EFA was performed on the MMO-2 items to determine if a similar structure pattern emerged. Parallel analysis suggested that nine factors be extracted from the MMO-2 items. Performing an EFA using PAF and an oblique rotation revealed that the nine factors accounted for $52.99 \%$ of the total variance, and examining the factor loadings showed that for the most part, items from the same scenario tended to cluster together.

It is evident from the results of these EFAs that variance due to the scenarios obscures the ability to examine the underlying moral orientation structure of these items. As such, a series of

\footnotetext{
${ }^{1}$ Factor loadings have not been reported because this analysis contained problematic items that would ordinarily be deleted. The loadings, however, are available upon request.
} 
EFAs were conducted on each scenario of the MMO-2 to determine if the care and justice orientations emerged in each scenario. A test of parallel analysis was conducted for the items of each scenario separately to determine the number of factors that should be extracted within each scenario. For five of the seven scenarios, two distinct factors emerged, with care items loading onto the first factor and justice items on the second. For the remaining two scenarios a three factor solution emerged in each case, with care and justice items loading onto each factor (see Table 2). These results seem to suggest that it is more beneficial to examine moral orientation structure at the scenario level, and to conceptualize the scenarios as parallel forms. Consequently, this was the factoring approach that was used for the AMO.

The results of the EFAs performed for each scenario of the AMO are reported in Tables 3 to 8. For each scenario, two to four factors emerge and in each case the extracted factors account for 38.98 to $55.82 \%$ of the total variance. The rotated factor loadings show that, in many instances, the items do load onto care, justice, and self-promotion factors, as hypothesized. However, there are instances of items with high cross-loadings and items with higher negative loadings on a factor other than its intended factor. Taken together with the previous item analyses, these results will be used to identify problematic items and inform future scale modifications.

\subsubsection{Analysis of Variance (ANOVA) on Instruction Set}

A series of single-factor ANOVAs were conducted using the General Linear Model approach to determine if mean scores on the proposed care, justice, and self-promotion scales differed significantly across instruction sets. Participants were randomly assigned to receive an instruction set that was either personal with personally-written scenarios (condition A), 
Table 2

EFA Factor Loadings for the MMO-2 by Scenario

\begin{tabular}{|c|c|c|c|c|}
\hline Item \# & Wording & Factor I & Factor II & Factor III \\
\hline \multicolumn{5}{|c|}{ Scenario 1} \\
\hline 1 & $\begin{array}{l}\text { I don't want to do anything that would jeopardize my } \\
\text { relationship with my roommate. }\end{array}$ & .678 & .232 & \\
\hline 4 & $\begin{array}{l}\text { The most important thing is my roommate not be hurt by } \\
\text { what happens. }\end{array}$ & .548 & -.102 & \\
\hline 6 & $\begin{array}{l}\text { I feel conflicted because I care about my friends, but I } \\
\text { also care about my roommate. }\end{array}$ & .484 & -.053 & \\
\hline 5 & I should try to be objective about this situation. & -.075 & .585 & \\
\hline 2 & $\begin{array}{l}\text { The members are entitled to their own opinions of all } \\
\text { prospective members. }\end{array}$ & .196 & .530 & \\
\hline 3 & $\begin{array}{l}\text { I don't want to do anything to influence the process of } \\
\text { membership selection. }\end{array}$ & -.065 & .418 & \\
\hline \multicolumn{5}{|c|}{ Scenario 2} \\
\hline 11 & $\begin{array}{l}\text { I would not do anything to harm my friendship with my } \\
\text { roommate. }\end{array}$ & .714 & -.077 & \\
\hline 10 & $\begin{array}{l}\text { I know how important graduation is and I don't want to } \\
\text { do anything that will keep my roommate from } \\
\text { graduating. }\end{array}$ & .643 & .030 & \\
\hline 7 & $\begin{array}{l}\text { I am hurt that my roommate did this, but I don't want to } \\
\text { make it bad for him/her. }\end{array}$ & .604 & -.142 & \\
\hline 15 & $\begin{array}{l}\text { I am worried about hurting my friendship with my } \\
\text { roommate. }\end{array}$ & .573 & -.122 & \\
\hline 13 & $\begin{array}{l}\text { I would seek a solution that would do the least harm to } \\
\text { both of us. }\end{array}$ & .400 & .179 & \\
\hline 8 & $\begin{array}{l}\text { Regardless of the consequences to my roommate, the } \\
\text { article was mine and I have a right to have it published. }\end{array}$ & -.128 & .736 & \\
\hline 14 & $\begin{array}{l}\text { Regardless of the reasons for doing so, my roommate } \\
\text { violated principles. }\end{array}$ & .012 & .623 & \\
\hline 12 & My roommate has an obligation to make this right. & .145 & .556 & \\
\hline 9 & $\begin{array}{l}\text { I should be objective and rational about this, and not let } \\
\text { my relationship cloud my judgment. }\end{array}$ & -.179 & .469 & \\
\hline \multicolumn{5}{|c|}{ Scenario 3} \\
\hline 22 & $\begin{array}{l}\text { We all need each other right now; no one should go } \\
\text { through this alone. }\end{array}$ & .673 & -.001 & \\
\hline 16 & $\begin{array}{l}\text { This is a matter of conflicting rights: Morgan's parents } \\
\text { have a right to know, but Morgan also has a right not to } \\
\text { tell them. }\end{array}$ & .625 & .060 & \\
\hline 18 & $\begin{array}{l}\text { I don't want to hurt Morgan but we can't continue to } \\
\text { overlook Morgan's parents' feelings; they feel hurt, too. }\end{array}$ & .527 & -.086 & \\
\hline
\end{tabular}

(continued) 
Table 2 (continued)

EFA Factor Loadings for the MMO-2 by Scenario

\begin{tabular}{|c|c|c|c|c|}
\hline Wording & & Factor I & Factor II & Factor III \\
\hline \multicolumn{5}{|c|}{ Scenario 3 (continued) } \\
\hline 20 & $\begin{array}{l}\text { The primary issue would be to look for a compromise } \\
\text { position which would keep both Morgan and Morgan's } \\
\text { parents from feeling hurt. }\end{array}$ & .497 & .046 & \\
\hline 21 & $\begin{array}{l}\text { I am concerned about maintaining my relationship with } \\
\text { Morgan's parents. }\end{array}$ & .304 & -.011 & \\
\hline 17 & $\begin{array}{l}\text { I made a promise and I should not break that promise no } \\
\text { matter what. }\end{array}$ & -.012 & .692 & \\
\hline 19 & $\begin{array}{l}\text { Morgan's needs are the most important and I have a duty } \\
\text { to respect those wishes. }\end{array}$ & .013 & 689 & \\
\hline \multicolumn{5}{|c|}{ Scenario 4} \\
\hline 24 & My primary concern is Karen's state of mind. & .962 & .121 & -.109 \\
\hline 26 & The most important thing is that Karen not get hurt. & .610 & -.014 & .084 \\
\hline 27 & $\begin{array}{l}\text { This is clearly a violation of the rules and should be } \\
\text { addressed. }\end{array}$ & -.105 & .781 & .018 \\
\hline 23 & I have a duty to do the right thing. & .155 & .665 & -.063 \\
\hline 28 & $\begin{array}{l}\text { Karen's reputation with her classmates and faculty is in } \\
\text { jeopardy here. }\end{array}$ & .012 & .274 & .203 \\
\hline 29 & $\begin{array}{l}\text { This is really about conflicting rights: Karen and the } \\
\text { professor's right to do what they want, and the rights of } \\
\text { the other students in the class to not be disadvantaged. }\end{array}$ & -.043 & .109 & .527 \\
\hline 30 & $\begin{array}{l}\text { I don't want to do anything to jeopardize my relationship } \\
\text { with Karen. }\end{array}$ & .163 & -.188 & .394 \\
\hline 25 & Karen has a right to her own business. & .200 & -.293 & .313 \\
\hline \multicolumn{5}{|c|}{ Scenario 5} \\
\hline 34 & $\begin{array}{l}\text { In spite of what we know, I would not want to be } \\
\text { responsible for causing harm to him and his family. }\end{array}$ & .681 & -.004 & \\
\hline 32 & $\begin{array}{l}\text { Whatever he did, he probably did so with his child in } \\
\text { mind. }\end{array}$ & .606 & .119 & \\
\hline 35 & $\begin{array}{l}\text { In order to hurt the least number of people, I should drop } \\
\text { the story, tell the administrator what I know, and ask him } \\
\text { to correct it quietly. }\end{array}$ & .486 & -.122 & \\
\hline 36 & $\begin{array}{l}\text { I would treat the administrator like everyone else, } \\
\text { regardless of his personal circumstances. }\end{array}$ & -.361 & .649 & \\
\hline 31 & $\begin{array}{l}\text { I would do what I thought was fair, regardless of the } \\
\text { consequences to myself or others. }\end{array}$ & .049 & .530 & \\
\hline 33 & $\begin{array}{l}\text { Regardless of the consequences, I am concerned about } \\
\text { the principles involved. }\end{array}$ & .041 & .481 & \\
\hline
\end{tabular}

(continued) 
Table 2 (continued)

EFA Factor Loadings for the MMO-2 by Scenario

\begin{tabular}{|c|c|c|c|c|}
\hline Item \# & Wording & Factor I & Factor II & Factor III \\
\hline \multicolumn{5}{|c|}{ Scenario 6} \\
\hline 42 & I don't want to be the one to hurt Richard with the news. & .801 & -.139 & \\
\hline 38 & $\begin{array}{l}\text { I do not want to be the one to cause harm to Richard's } \\
\text { relationship with Amy. }\end{array}$ & .640 & -.053 & \\
\hline 40 & $\begin{array}{l}\text { My reaction would depend upon how Richard really feels } \\
\text { about Amy. }\end{array}$ & .424 & -.137 & \\
\hline 37 & $\begin{array}{l}\text { The most important thing to me is that my brother } \\
\text { Richard not get hurt. }\end{array}$ & .334 & .371 & \\
\hline 41 & $\begin{array}{l}\text { Amy violated the rules of their relationship and Richard } \\
\text { should know. }\end{array}$ & -.060 & .887 & \\
\hline 44 & Richard has a right to know that Amy is cheating. & -.091 & .753 & \\
\hline 39 & $\begin{array}{l}\text { I would tell Richard because if I were in his situation I } \\
\text { would want him to tell me. }\end{array}$ & -.142 & .733 & \\
\hline 43 & $\begin{array}{l}\text { I would do what I thought was fair, regardless of the } \\
\text { consequences. }\end{array}$ & -.116 & .533 & \\
\hline \multicolumn{5}{|c|}{ Scenario 7} \\
\hline 47 & $\begin{array}{l}\text { What I wish more than anything is to make everyone } \\
\text { happy and not hurt them. }\end{array}$ & .818 & -.034 & -.043 \\
\hline 48 & $\begin{array}{l}\text { I don't want anything to come between my parents and } \\
\text { me. }\end{array}$ & .803 & -.127 & .194 \\
\hline 52 & $\begin{array}{l}\text { I will do the objective thing - split my time between both } \\
\text { of them. }\end{array}$ & .563 & .212 & -.095 \\
\hline 46 & I have an obligation to both my parents right now. & .494 & .236 & -.287 \\
\hline 45 & I have the right to spend time with whomever I want. & .451 & .047 & .222 \\
\hline 50 & $\begin{array}{l}\text { Everyone has the right to happiness, even if the } \\
\text { consequences are sometimes hurtful to others. }\end{array}$ & -.061 & .604 & .051 \\
\hline 51 & $\begin{array}{l}\text { In spite of what my mother did, I would not to anything } \\
\text { to hurt her. }\end{array}$ & .214 & .579 & .092 \\
\hline 49 & $\begin{array}{l}\text { What I did would depend on how I thought each parent } \\
\text { needed me. }\end{array}$ & .091 & .170 & .539 \\
\hline
\end{tabular}


Table 3

EFA Factor Loadings for the AMO Impersonal Version Scenario 1 (Student/Teacher Relationships)

\begin{tabular}{|c|c|c|c|c|c|}
\hline Item & Wording & $\begin{array}{c}\text { Factor } \\
\mathrm{I}\end{array}$ & $\begin{array}{c}\text { Factor } \\
\text { II }\end{array}$ & $\begin{array}{c}\text { Factor } \\
\text { III }\end{array}$ & $\begin{array}{l}\text { Factor } \\
\text { IV }\end{array}$ \\
\hline 2 & $\begin{array}{l}\text { James has a responsibility to report his } \\
\text { relationship with Kelly to the school. }\end{array}$ & .668 & -.029 & .002 & .360 \\
\hline 5 & $\begin{array}{l}\text { Kelly would feel uncomfortable violating } \\
\text { school policy. }\end{array}$ & .530 & .054 & .116 & -.131 \\
\hline 3 & $\begin{array}{l}\text { Kelly could use this opportunity to boost her } \\
\text { average for graduation. }\end{array}$ & -.359 & .576 & .008 & .335 \\
\hline 1 & $\begin{array}{l}\text { If Kelly and James really like each other, they } \\
\text { should do what is best for their relationship. }\end{array}$ & -.272 & -.036 & .071 & .127 \\
\hline 13 & $\begin{array}{l}\text { If Kelly ends the relationship, James may be } \\
\text { angry and purposely give her low grades. }\end{array}$ & .008 & .455 & -.085 & .000 \\
\hline 11 & $\begin{array}{l}\text { School policies are put in place for situations } \\
\text { exactly like this one. }\end{array}$ & .227 & .340 & .039 & -.267 \\
\hline 7 & $\begin{array}{l}\text { Kelly's reputation with her classmates could be } \\
\text { in jeopardy if they became aware of her } \\
\text { relationship. }\end{array}$ & .155 & .331 & .116 & -.085 \\
\hline 10 & $\begin{array}{l}\text { Kelly would feel guilty if James lost his job } \\
\text { because of their relationship. }\end{array}$ & .050 & -.085 & .659 & .046 \\
\hline 6 & $\begin{array}{l}\text { Breaking school policy could threaten Kelly's } \\
\text { graduation. }\end{array}$ & .299 & .123 & .449 & -.049 \\
\hline 4 & Kelly would not want to hurt James. & -.129 & -.009 & .440 & -.021 \\
\hline 9 & $\begin{array}{l}\text { Kelly needs to forget about others and think } \\
\text { about what is best for her. }\end{array}$ & .106 & .138 & -.018 & .561 \\
\hline 8 & $\begin{array}{l}\text { This is really about conflicting rights: their right } \\
\text { to do what they want, and the rights of other } \\
\text { students in the class to be treated fairly. }\end{array}$ & .039 & .079 & .021 & -.256 \\
\hline
\end{tabular}


Table 4

EFA Factor Loadings for AMO Impersonal Version Scenario 2 (Refugees)

\begin{tabular}{|c|c|c|c|c|}
\hline Item & Wording & $\begin{array}{c}\text { Factor } \\
\mathrm{I}\end{array}$ & $\begin{array}{c}\text { Factor } \\
\text { II }\end{array}$ & $\begin{array}{c}\text { Factor } \\
\text { III }\end{array}$ \\
\hline 20 & $\begin{array}{l}\text { Showing compassion is more important than following } \\
\text { the rules. }\end{array}$ & .765 & -.155 & .035 \\
\hline 17 & $\begin{array}{l}\text { Makayla should focus on giving help where it is needed } \\
\text { most. }\end{array}$ & .541 & -.032 & -.288 \\
\hline 14 & $\begin{array}{l}\text { There are situations where following policy isn't the } \\
\text { best choice. }\end{array}$ & .367 & -.005 & -.542 \\
\hline 21 & Makayla cannot let emotions cloud her judgment. & .373 & .440 & .059 \\
\hline 16 & $\begin{array}{l}\text { If Makayla does not follow her government's policy, } \\
\text { she could be fired. }\end{array}$ & -.049 & .605 & .107 \\
\hline 15 & $\begin{array}{l}\text { Makayla should be objective when making her } \\
\text { decisions. }\end{array}$ & -.142 & .357 & -.095 \\
\hline 18 & It is important to always follow policy. & -.020 & .131 & .636 \\
\hline 23 & $\begin{array}{l}\text { Makayla will only get ahead in her career if she follows } \\
\text { the rules. }\end{array}$ & .053 & .034 & .401 \\
\hline 19 & $\begin{array}{l}\text { Makayla does not personally benefit from helping the } \\
\text { sick applicants, so why bother? }\end{array}$ & -.030 & -.161 & .381 \\
\hline
\end{tabular}


Table 5

EFA Factor Loadings for AMO Impersonal Version Scenario 3 (Drunk Driving)

\begin{tabular}{|c|c|c|c|}
\hline Item & Wording & Factor I & Factor II \\
\hline 28 & Joe should treat the driver the same as any other offender. & .739 & .114 \\
\hline 25 & Driving while impaired is extremely dangerous. & 691 & -.046 \\
\hline 33 & Innocent people could be hurt if the man drives home. & .568 & -.109 \\
\hline 31 & There are no excuses for allowing someone to drive drunk. & .553 & -.097 \\
\hline 29 & $\begin{array}{l}\text { It is not Joe's responsibility to clean up the mistakes of other } \\
\text { people. }\end{array}$ & .445 & .201 \\
\hline 26 & Joe should not do anything that could jeopardize his own job. & .418 & .431 \\
\hline 34 & Joe should be objective. & .317 & .021 \\
\hline 24 & Joe's primary concern is the driver's safety. & .229 & .191 \\
\hline 30 & $\begin{array}{l}\text { The late hour and empty roads make it less likely the driver } \\
\text { will have an accident. }\end{array}$ & -.236 & .176 \\
\hline 32 & $\begin{array}{l}\text { If Joe makes exceptions for people, he will never get ahead in } \\
\text { his career. }\end{array}$ & .029 & .445 \\
\hline 36 & $\begin{array}{l}\text { If Joe does the driver a favour, he should get something in } \\
\text { return. }\end{array}$ & -.611 & .381 \\
\hline 27 & The driver's financial livelihood is at risk. & .019 & .227 \\
\hline
\end{tabular}


Table 6

EFA Factor Loadings for AMO Impersonal Version Scenario 4 (Cheating)

\begin{tabular}{|c|c|c|c|}
\hline Item & Wording & Factor I & Factor II \\
\hline 38 & Dan has a right to know that Alex is cheating. & .718 & -.063 \\
\hline 41 & $\begin{array}{l}\text { Regardless of Alex's reasons, the rules of her relationship with } \\
\text { Dan have been violated. }\end{array}$ & .689 & -.041 \\
\hline 44 & Alex should be held accountable for her actions. & .675 & .008 \\
\hline 48 & $\begin{array}{l}\text { Under no circumstances is it acceptable for someone to cheat in a } \\
\text { relationship. }\end{array}$ & .637 & .002 \\
\hline 43 & $\begin{array}{l}\text { If Alex is cheating on Dan, their relationship must not be as happy } \\
\text { as Jordan thought. }\end{array}$ & .427 & .106 \\
\hline 39 & Jordan could damage his own relationship with Jamie. & -.139 & .553 \\
\hline 37 & The most important thing is for Dan not to be hurt. & .083 & .538 \\
\hline 42 & $\begin{array}{l}\text { If Jordan tells Dan the truth, he may become angry at Jordan and } \\
\text { choose to believe Alex instead. }\end{array}$ & -.019 & .522 \\
\hline 40 & Jordan would not cause harm to someone else's relationship. & -.068 & .444 \\
\hline 46 & Jordan's decision will have an impact on all four friends. & .162 & .311 \\
\hline 45 & $\begin{array}{l}\text { Jordan could keep this information to himself and use it against } \\
\text { Alex when it is most beneficial for him. }\end{array}$ & -.320 & .288 \\
\hline
\end{tabular}


Table 7

EFA Factor Loadings for AMO Impersonal Version Scenario 5 (Assisted Suicide)

\begin{tabular}{|c|c|c|c|}
\hline Item & Wording & Factor I & Factor II \\
\hline 53 & It is never okay to help someone end their life. & .762 & .339 \\
\hline 58 & $\begin{array}{l}\text { In some cases, letting someone suffer is worse than } \\
\text { helping them die. }\end{array}$ & -.678 & .113 \\
\hline 59 & $\begin{array}{l}\text { The patient has the right to make her own decisions about } \\
\text { her health care, within the limits of the law. }\end{array}$ & -.558 & .158 \\
\hline 55 & $\begin{array}{l}\text { If their roles were reversed, Susan would hope her own } \\
\text { doctor would consider her wishes. }\end{array}$ & -.500 & .224 \\
\hline 50 & Helping anyone commit suicide is morally wrong. & .498 & .429 \\
\hline 61 & This is not Susan's problem to solve. & .359 & .063 \\
\hline 51 & Susan could get into serious trouble. & -.187 & .752 \\
\hline 52 & $\begin{array}{l}\text { Susan could threaten her relationships with her } \\
\text { colleagues. }\end{array}$ & .066 & .586 \\
\hline 49 & It would greatly upset Susan to see her patient in pain. & -.283 & .492 \\
\hline 57 & The risk of being caught is too high. & -.013 & .460 \\
\hline 56 & $\begin{array}{l}\text { Susan has a responsibility to tell her boss of the patient's } \\
\text { intentions. }\end{array}$ & .214 & .352 \\
\hline
\end{tabular}


Table 8

EFA Factor Loadings for AMO Impersonal Version Scenario 6 (Plagarism)

\begin{tabular}{|c|c|c|c|}
\hline Item & Wording & Factor I & Factor II \\
\hline 66 & $\begin{array}{l}\text { Plagiarism is a serious offence for a journalist and Glen should be } \\
\text { punished. }\end{array}$ & .741 & .061 \\
\hline 64 & Mark wrote the article and deserves all the credit. & .663 & -.137 \\
\hline 69 & Copying another person's work is never acceptable. & .602 & .004 \\
\hline 72 & $\begin{array}{l}\text { Under no circumstances is it acceptable to take credit for another } \\
\text { person's work. }\end{array}$ & .588 & .146 \\
\hline 63 & $\begin{array}{l}\text { Regardless of the consequences, the editor should be made } \\
\text { aware of the truth. }\end{array}$ & .566 & -.043 \\
\hline 67 & Mark will only get ahead in his career if he stands up for himself. & .520 & -.066 \\
\hline 74 & It is okay for Mark to do what is best for himself. & .468 & -.021 \\
\hline 68 & Mark is a student and still learning from Glen. & -.230 & .687 \\
\hline 62 & Mark could threaten his relationship with Glen. & .237 & .541 \\
\hline 71 & $\begin{array}{l}\text { Glen is the professional, and without him Mark would not have } \\
\text { anything published. }\end{array}$ & -.117 & .345 \\
\hline 65 & $\begin{array}{l}\text { Mark has a right to be hurt by Glen's actions, but he should also } \\
\text { show respect for his superior. }\end{array}$ & -.300 & .332 \\
\hline 70 & Mark should do what is best for his career in the long-term. & .229 & .277 \\
\hline
\end{tabular}


impersonal with impersonally-written scenarios (condition B), or semi-personal with impersonally-written scenarios (condition C).

First, care means were compared across all three conditions. Levene's test of homogeneity of variances was not significant and so equal variances were assumed, $F(2,197)=$ $1.591, n s$. The results of the ANOVA were not significant, $F(2,197)=.695, n s$. Therefore, care means did not differ as a function of instruction set.

Next, justice means were compared. Once again, neither Levene's test of homogeneity of variances, $F(2,197)=1.055, n s$, nor the ANOVA were significant, $F(2,197)=.716, n s$. Therefore, instruction set did not seem to have an effect on justice scores.

Lastly, the effect of the instructions on self-promotion scores was examined. Again, Levene's test of homogeneity of variances was not significant, and equal variances between groups were assumed, $F(2,197)=1.116, n s$. The ANOVA revealed that mean self-promotion scores differed significantly across conditions, $F(2,197)=3.935, p<.05$. Post hoc tests of means using a Bonferroni adjustment were conducted to determine which means differed significantly from one another. The Bonferroni approach was selected to control the Type I error rate. It was found that participants in condition A $(M=3.12, S D=0.43)$ scored significantly lower on selfpromotion than did those in condition $\mathrm{B}(M=3.29, S D=0.35), t(197)=-2.49, p<.05$. However, self-promotion scores did not differ significantly between conditions $\mathrm{A}$ and $\mathrm{C}(M=3.28, S D=$ $0.40), t(197)=-2.30, n s$, nor between conditions $\mathrm{B}$ and $\mathrm{C}, t(197)=0.08, n s$.

\subsection{Discussion}

Study 1 was conducted to pilot-test preliminary items for the AMO, and to determine the effect of scenario content and instruction set on moral orientation scores. In line with previous research (Wark \& Krebs, 2000) scenario content was found to have an effect on moral 
orientation scores. However, the present study did not find a significant effect on care or justice scores. Rather, it was found that self-promotion scores were lower among personal scenarios with personal instructions as compared to impersonal scenarios with impersonal instructions, and the difference was minimal. Keeping in mind the unvalidated nature of the moral orientation scale used in this study, these results were interpreted only to inform the modification of the AMO for Study 2. Because minimal effect of instruction set was found, and there is arguably more utility in a moral orientation scale that assesses the factors one would consider when put in a moral dilemma themselves, in Study 2 all participants were presented with the personal scenarios and personal instruction set (condition A).

Although the item analyses conducted in Study 1 were helpful in identifying a number of problematic items, no additional scale modifications were made before administering the AMO in Study 2. This decision was reached for a number of reasons. First, only condition A was administered in Study 2, and to make modifications to these items would have meant making decisions based on a small sample of participants $(N=73)$. In addition, the sample in Study 1 consisted entirely of undergraduate students with a very restricted age range who are likely not representative of the larger population. As such, the results of Study 1 and 2 will be taken together to inform further modifications of the AMO. 


\section{CHAPTER THREE: STUDY 2 - ITEM REFINEMENT AND CONSTRUCT VALIDITY}

Following the results of Study 1 the AMO was administered to a large community sample in Study 2. The goal of Study 2 was to refine the items of the AMO and to reduce its overall length. In addition, Study 2 also sought to provide preliminary construct validity by examining correlations between the AMO, the Dark Triad, and the HEXACO personality traits.

\subsection{Method}

\subsubsection{Participants}

The sample for Study 2 consisted of 326 North American participants (92 male, 233 female, 1 unspecified) recruited online via Crowdflower. Participants ranged in age from 18 to 69 years $(M=37.59, S D=11.99)$ and were compensated 50 cents for their participation in the study. Fifty cents is the maximum compensation allowed by Crowdflower, and participants rated the fairness of pay as 4.2 out of 5 .

The majority of the sample identified themselves as White $(75.8 \%)$, followed by Chinese (6.4\%), Black (5.2\%), and South Asian (3.4\%). The remaining 9.8\% of the sample identified themselves as Latin American (1.8\%), Filipino (1.5\%), Southeast Asian (1.2\%), Arab, West Asian, Korean, or Japanese (0.3\% each), mixed (2.1\%), or other (1.2\%). Tests of proportions were computed to determine if these values differed significantly from population statistics collected from Statistics Canada during the 2011 census (Statistics Canada, 2011). It was found that ethnicity proportions in this sample differed significantly from census data, $X^{2}=40.717, p<$ .05. In particular, the sample contained a greater percentage of Black, Latin American, East Asian (Chinese, Korean, and Japanese), and mixed participants, whereas Arab, West Asian, and Southeast Asian cultures were underrepresented. 
Data on religious affiliation were also collected from participants. The majority of the sample reported having no religious affiliation (28.5\%), or identified as Christian not-otherwisestated $(23.3 \%)$ or Catholic (19\%). The remaining participants identified as Protestant (14.1\%), Christian Orthodox (3.1\%), Muslim (3.1\%), Hindu (2.1\%), Buddhist (1.8\%), Jewish (0.6\%) or other (4.0\%). Again, these values were compared to national statistics (Statistics Canada, 2011) and it was found that the sample proportions differed significantly from census data, $X^{2}=1$ $368.53, p<.001$. In particular, the sample contained a greater proportion of individuals identifying as Christian not-otherwise-stated or with no religious affiliation, and significantly lower proportions of participants identifying as Protestant or Christian Orthodox.

\subsubsection{Materials and Procedures}

Assessment of Moral Orientation (AMO). See Chapter 2 for a detailed description of the development of the AMO. The version used in Study 2 contained six personally written moral dilemmas (see Appendix A). After reading each dilemma, participants responded to items that were written to reflect a care, justice, or self-promotion moral orientation. A total of 74 items were included, six of which were items to check for careless responding and not used to compute final scale scores. Participants responded to items on a 5-point Likert scale, with higher scores reflecting a greater endorsement of the orientation $(1=$ extremely unlikely, $5=$ extremely likely).

Measure of Moral Orienation-2 (MMO-2). See Chapter 2 for a description of this measure.

Balanced Inventory of Desirable Responding (BIDR-6). See Chapter 2 for a detailed description of this assessment. 
Short-D3 (SD3). The SD3 (Jones \& Paulhus, 2014) is a 27-item self report measure of the Dark Triad. The Dark Triad consists of three distinct but related personality traits: Machiavellianism, narcissism, and psychopathy. Items are measured on a 5-point Likert scale (1 = Disagree Strongly, 5 = Agree Strongly). Example items include "I like to use clever manipulation to get my way" (Machiavellianism), "People see me as a natural leader" (narcissism), and "I like to get revenge on authorities" (psychopathy). Jones \& Paulhus (2014) reported Cronbach's alphas ranging from .71 to .80 for each subscale.

HEXACO-60. The HEXACO-60 (Ashton \& Lee, 2009) is a 60-item self-report measure of six major dimensions of personality: Honesty-humility ("I wouldn't use flattery to get a raise or promotion at work, even if I thought it would succeed.”), Emotionality("I would feel afraid if I had to travel in bad weather conditions."), Extraversion ("In social situations, I'm usually the one who makes the first move."), Agreeableness ("I rarely hold a grudge, even against people who have badly wronged me."), Conscientiousness ("I plan ahead and organize things, to avoid scrambling at the last minute."), and Openness to Experience ("I would enjoy creating a work of art, such as a novel, a song, or a painting."). Items are assessed on a 5-point Likert scale, with higher scores reflecting greater endorsement of the item. Ashton and Lee (2009) reported Cronbach's reliability estimates ranging from .76 to .80 , indicating good internal consistency.

\subsubsection{Procedure}

A digital recruitment poster for the present study was posted on Crowdflower. Interested participants received a URL directing them to the study, which was presented via FluidSurvey. Participants first read the letter of information, which stated that the completion of the survey indicated an individual's consent to participate. Only participants who were 18 years of age or older and fluent in English were eligible to participate. 
After reading the letter of information participants completed the AMO, MMO-2, SD3, HEXACO-60, and BIDR-6, in that order. Upon completion participants were debriefed and asked to enter an alphanumeric code into the original Crowdflower webpage. This code allowed participants to be paid through the Crowdflower website.

\subsection{Results}

\subsubsection{Careless Responders}

Once again, a series of tests was performed to test for careless responders. These procedures were the same as those described in Study 1, with one additional test. The responses of any participants who entered the incorrect alphanumeric code into the Crowdflower webpage were deleted as this was taken as a sign of inattentive responding. Following all tests of careless responding the sample was reduced from 400 to 326.

\subsubsection{Item Level Analyses}

As in Study 1, item retention decisions were based on a number of criteria. Each response item was assessed for adequate variability (Jackson, 1970) and adjusted item-total correlations (Dozoi et al., 1998). In addition, to reduce overlap between subscales, items that correlated highly with scales other than their own $(r>.20)$ were considered for deletion. Lastly, to reduce the impact of socially desirable responding any item that correlated $(r>.20)$ with the SDE and IM subscales of the BIDR-6 were also considered for deletion.

Following these analyses, 34 of the 68 response items were retained, with 12 items comprising the care subscale, 13 the justice subscale, and 9 the self-promotion subscale. It is important to note that all four self-promotion items from scenario six were deleted. Descriptive statistics and Cronbach's alphas for the AMO after item analyses are reported in Table 9. 
Table 9

Study 2 Descriptive Statistics

\begin{tabular}{|c|c|c|c|c|c|c|}
\hline \multirow[t]{2}{*}{ Subscale } & \multicolumn{2}{|c|}{ Males } & \multicolumn{2}{|c|}{ Females } & \multirow[t]{2}{*}{$\mathrm{t}$} & \multirow{2}{*}{$\begin{array}{c}\text { Cronbach's } \\
\text { Alpha }\end{array}$} \\
\hline & $M$ & $S D$ & $M$ & $S D$ & & \\
\hline \multicolumn{7}{|l|}{ AMO } \\
\hline Care & 3.67 & 0.45 & 3.86 & 0.46 & $-3.23 * *$ & .60 \\
\hline Justice & 3.84 & 0.53 & 4.10 & 0.49 & $-4.17 * *$ & .74 \\
\hline Self-Promotion & 3.02 & 0.79 & 2.70 & 0.66 & $3.96 * *$ & .75 \\
\hline \multicolumn{7}{|l|}{ MMO-2 } \\
\hline Care & 2.93 & 0.40 & 3.10 & 0.36 & $-3.67 * *$ & .86 \\
\hline Justice & 3.14 & 0.37 & 3.28 & 0.32 & $-3.30 * *$ & .83 \\
\hline \multicolumn{7}{|l|}{ Short-D3 } \\
\hline Machiavellianism & 3.22 & 0.63 & 2.93 & 0.73 & $3.34^{* *}$ & .81 \\
\hline Narcissism & 2.90 & 0.52 & 2.53 & 0.61 & $5.53 * *$ & .71 \\
\hline Psychopathy & 2.56 & 0.74 & 2.00 & 0.73 & $6.27^{* *}$ & .83 \\
\hline \multicolumn{7}{|l|}{ HEXACO-60 } \\
\hline Honesty-Humility & 3.23 & 0.51 & 3.59 & 0.61 & $-5.40 * *$ & .68 \\
\hline Emotionality & 3.01 & 0.52 & 3.46 & 0.57 & $-6.55 * *$ & .73 \\
\hline Extraversion & 3.12 & 0.52 & 3.02 & 0.67 & 1.39 & .77 \\
\hline Agreeableness & 3.16 & 0.39 & 3.17 & 0.52 & -0.22 & .58 \\
\hline Conscientiousness & 3.35 & 0.54 & 3.57 & 0.62 & $-2.99 *$ & .75 \\
\hline Openness & 3.25 & 0.62 & 3.40 & 0.66 & -1.80 & .73 \\
\hline
\end{tabular}

$*$ indicates significance at $p<.01$

$* *$ indicates significance at $p<.001$ 


\subsubsection{Exploratory Factor Analyses}

As demonstrated in Study 1, it can be difficult to extract clear factors reflecting personality dimensions when a measure contains a variety of scenarios. Therefore, in order to factor analyze the AMO, each scenario was conceptualized as a parallel form of the same test. As such, a separate EFA using principal axis factoring was performed on each scenario, with three factors expected in each case. Oblique rotation was performed in each case to allow subscales to correlate, as they were expected. As recommended by O'Connor (2000) parallel analysis was performed for each scenario to determine how many factors to extract.

For the first scenario (Student/Teacher Relationships), the results of the parallel analysis suggested a three factor solution. The three extracted factors accounted for $63.60 \%$ of the variance. Justice items were found to load exclusively onto factor I, care items onto factor II, and self-promotion items onto factor III. Factor loadings are reported in Table 10. As expected, factors I and II were moderately correlated with one another $(r=.191, p<.001)$. However, factors I and III $(r=-.078, n s)$, and II and III $(r=-.045, n s)$ were not correlated significantly.

In the second scenario (Refugees), parallel analysis suggested a two factor solution, which accounted for $59.30 \%$ of the variance. After extracting two factors, it was found that the first factor contained high loadings from all the care items, whereas the second factor contained high loadings from the self-promotion items. Justice items were found to load positively onto factor I, and negatively onto factor II. These results are reported in Table 11. In addition, factors I and II were found to be significantly negatively correlated with one another $(r=-.437, p<$ $.001)$.

An EFA was also performed on the third scenario (Drunk Driving). Once again, parallel analysis suggested a two factor solution. These factors were found to account for $54.75 \%$ of the 
Table 10

Study 2 EFA Factor Loadings for Scenario 1 (Student/Teacher Relationships)

\begin{tabular}{|c|c|c|c|c|}
\hline Item & Wording & $\begin{array}{c}\text { Factor } \\
\text { I }\end{array}$ & $\begin{array}{c}\text { Factor } \\
\text { II }\end{array}$ & $\begin{array}{c}\text { Factor } \\
\text { III }\end{array}$ \\
\hline 2 & $\begin{array}{l}\text { My teacher has a responsibility to report his/her } \\
\text { relationship with me to the school. }\end{array}$ & .435 & .004 & .022 \\
\hline 11 & $\begin{array}{l}\text { I think school policies are put in place for situations } \\
\text { exactly like this one. }\end{array}$ & .532 & .085 & .022 \\
\hline 4 & I would not want to hurt my partner. & -.027 & .471 & .076 \\
\hline 10 & $\begin{array}{l}\text { I would feel guilty if my partner lost his/her job } \\
\text { because of our relationship. }\end{array}$ & .154 & .599 & -.178 \\
\hline 9 & $\begin{array}{l}\text { I need to forget about others and think about what is } \\
\text { best for me. }\end{array}$ & -.262 & .068 & .456 \\
\hline 13 & $\begin{array}{l}\text { If I end the relationship, my partner may be angry and } \\
\text { purposely give me low grades. }\end{array}$ & .162 & -.044 & .417 \\
\hline
\end{tabular}


Table 11

Study 2 EFA Factor Loadings for Scenario 2 (Refugees)

\begin{tabular}{llcr}
\hline Item & Wording & Factor I & Factor II \\
\hline 17 & I would focus on giving help where it is needed most. & .694 & .057 \\
20 & Showing compassion is more important than following the & .727 & -.045 \\
& $\begin{array}{l}\text { rules. } \\
21\end{array} \quad$ I cannot let emotions cloud my judgment. & -.230 & .237 \\
19 & I do not personally benefit from helping the sick applicants, so & -.066 & .302 \\
& why bother. & .125 & .854 \\
\hline
\end{tabular}


variance. As reported in Table 12, factor I contained high loadings from both the care and justice items, whereas factor II consisted of high loadings from only the self-promotion items. Interestingly factors I and II did not appear to be significantly associated for this scenario $(r=$ $.063, n s)$.

A similar pattern of results was observed for the fourth scenario (Cheating), with parallel analysis again suggesting a two factor solution accounting for $55.43 \%$ of the variance. However, for the fourth scenario, care items loaded highly onto the first factor; whereas justice and selfpromotion items loaded highly onto the second factor (see Table 13). In addition, factors I and II were moderately positively correlated with one another $(r=.192, p<.001)$.

The results of the parallel anlaysis performed on the fifth scenario (Assisted Suicide) suggested a three factor solution. Consequently, three factors were extracted, and found to account for $78.05 \%$ of the variance. As reported in Table 14, justice items loaded exclusively onto factor I, self-promotion items onto factor II, and care items onto factor III. Interestingly, factors I and II were positively correlated $(r=.229, p<.001)$ and factors I and III were negatively correlated $(r=-.503, p<.001)$. However, factors II and III were not significantly $\operatorname{associated}(r=-.014, n s)$.

For the final scenario (Plagiarism), a two-factor structure was expected given that all selfpromotion items were deleted due to a failure to meet basic psychometric properties conducted during the item analyses. The results of the parallel analysis indeed suggested a two factor solution. As such, two factors were extracted, and these factors accounted for $66.82 \%$ of the variance. Factor loadings are presented in Table 15. As can be seen in this table, factor I contained high loadings from justice items, whereas factor II contained high loadings from the 
Table 12

Study 2 EFA Factor Loadings for Scenario 3 (Drunk Driving)

\begin{tabular}{|c|c|c|c|}
\hline Item & Wording & Factor I & Factor II \\
\hline 28 & I should treat my uncle the same as any other offender. & .779 & -.015 \\
\hline 31 & There are no excuses for allowing someone to drive drunk. & .532 & .174 \\
\hline 29 & $\begin{array}{l}\text { It is not my responsibility to clean up the mistakes of other } \\
\text { people. }\end{array}$ & .476 & -.103 \\
\hline 32 & $\begin{array}{l}\text { If I make exceptions for people, I will never get ahead in my } \\
\text { career. }\end{array}$ & .458 & -.043 \\
\hline 24 & My primary concern is my uncle's safety. & .090 & .677 \\
\hline 27 & My uncle's financial livelihood is at risk. & -.083 & .444 \\
\hline
\end{tabular}


Table 13

Study 2 EFA Factor Loadings for Scenario 4 (Cheating)

\begin{tabular}{|c|c|c|c|}
\hline Item & Wording & Factor I & Factor II \\
\hline 38 & Jessie has a right to know that Alex is cheating. & .645 & .111 \\
\hline 41 & $\begin{array}{l}\text { Regardless of Alex's reasons, the rules of his/her relationship } \\
\text { with Jessie have been violated. }\end{array}$ & .678 & .050 \\
\hline 48 & $\begin{array}{l}\text { Under no circumstances is it acceptable for someone to cheat in } \\
\text { a relationship. }\end{array}$ & .672 & -.039 \\
\hline 45 & $\begin{array}{l}\text { I could keep this information to myself and use it against Alex } \\
\text { when it is most beneficial to me. }\end{array}$ & -.338 & .104 \\
\hline 37 & The most important thing is for Jessie not to be hurt. & -.022 & .691 \\
\hline 46 & My decision will have an impact on all four of us being friends. & .310 & .221 \\
\hline
\end{tabular}


Table 14

Study 2 EFA Factor Loadings for Scenario 5 (Assisted Suicide)

\begin{tabular}{|c|c|c|c|c|}
\hline Item & Wording & $\begin{array}{c}\text { Factor } \\
\mathrm{I}\end{array}$ & $\begin{array}{c}\text { Factor } \\
\text { II }\end{array}$ & $\begin{array}{c}\text { Factor } \\
\text { III }\end{array}$ \\
\hline 50 & $\begin{array}{l}\text { I believe helping anyone commit suicide is morally } \\
\text { wrong. }\end{array}$ & .722 & .062 & -.127 \\
\hline 53 & It is never okay to help someone end their life. & .941 & .021 & .060 \\
\hline 54 & $\begin{array}{l}\text { My grandmother's death is certain, and I could use the } \\
\text { inheritance money sooner rather than later. }\end{array}$ & -.079 & .769 & .017 \\
\hline 61 & This is not my problem to solve. & .148 & .471 & -.028 \\
\hline 55 & $\begin{array}{l}\text { If our roles were reversed, I would hope my } \\
\text { grandmother would consider my wishes }\end{array}$ & -.237 & .179 & .656 \\
\hline 58 & $\begin{array}{l}\text { In some cases, letting someone suffer is worse than } \\
\text { helping them die. }\end{array}$ & .063 & -.067 & .642 \\
\hline
\end{tabular}


Table 15

Study 2 EFA Factor Loadings for Scenario 6 (Plagiarism)

\begin{tabular}{llcc}
\hline Item \# & Wording & Factor I & Factor II \\
\hline 63 & $\begin{array}{l}\text { Regardless of the consequences, the editor should be } \\
\text { made aware of the truth. }\end{array}$ & .687 & .054 \\
66 & $\begin{array}{l}\text { Plagiarism is a serious offence for a journalist and Glen } \\
\text { should be punished. }\end{array}$ & .683 & -.019 \\
72 & $\begin{array}{l}\text { Under no circumstances is it acceptable to take credit for } \\
\text { another person's work. }\end{array}$ & .780 & -.033 \\
62 & $\begin{array}{l}\text { I could threaten my relationship with Glen. } \\
68\end{array}$ & I am a student and still learning from Glen. & .226 \\
\hline
\end{tabular}


care items. However, these two factors were not positively correlated, as expected $(r=-.023$, $n s)$.

\subsubsection{Sex Differences}

A series of independent samples $t$-tests were conducted to determine if men and women differed significantly on any of the measured constructs. The results of these analyses are presented in Table 9. Interestingly, women scored higher than did men on both care and justice moral orientations, as assessed with the AMO and MMO-2. In addition, men scored higher on the self-promotion subscale of the AMO than did women. Consistent with previous research, men scored significantly higher than did women on Machiavellianism, narcissism, and psychopathy. Lastly, women reported significantly higher Honesty-Humility, Emotionality, and Conscientiousness scores than did men.

\subsubsection{Convergent and Construct Validity}

Zero-order correlations between the AMO, MMO-2, Short-D3, and HEXACO-60 are reported in Table 16. As expected, the care and justice subscales of the AMO were positively correlated with one another $(r=.31, p<.001)$. Counter to predictions, the self-promotion scale was not significantly correlated with care or with justice.

Evidence of convergent validity for the AMO was found, with high correlations between the care subscales of the AMO and MMO-2 $(r=.59, p<.001)$, and between the justice subscales of these two measures $(r=.62, p<.001)$. In addition, the care subscale of the AMO was positively correlated with the justice subscale of the MMO-2 $(r=.50, p<.001)$ and the justice subscale of the AMO was positively correlated with the care subscale of the MMO-2 $(r=$ $.44, p<.001)$. Once again, the self-promotion subscale of the AMO was not significantly associated with either the care or justice subscales of the MMO-2. 
Table 16

Study 2 Zero-Order Correlations

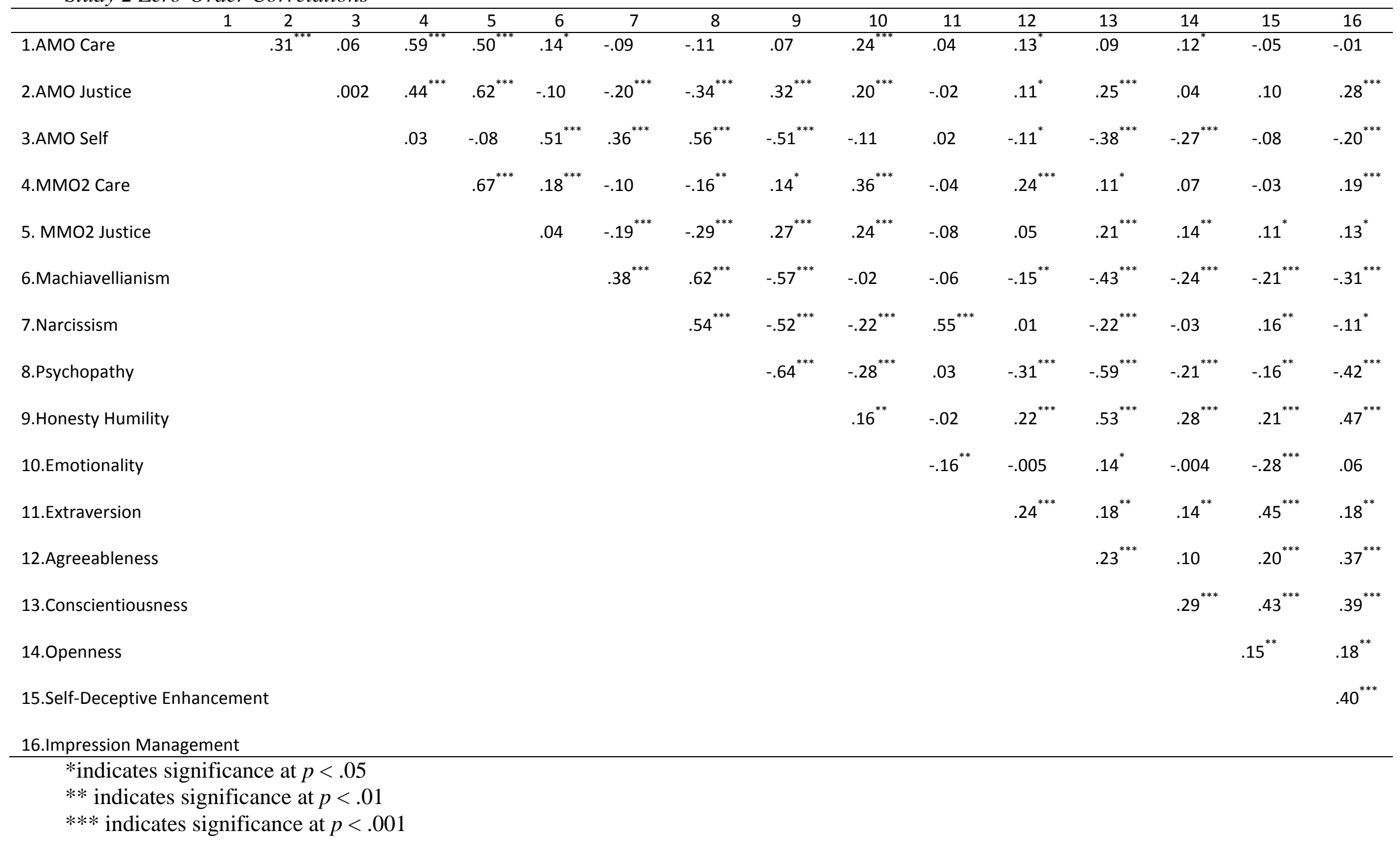


It was hypothesized that a care moral orientation would be negatively correlated with each of the Dark Triad traits. Furthermore, it was expected that the strongest negative association between care and the Dark Triad would be with psychopathy. However, contrary to predictions AMO and MMO-2 care were both found to correlate positively (although weakly) with Machiavellianism $(r=.14, p<.05$ and $r=.18, p<.05$ respectively). Furthermore, no significant associations were observed between care and narcissism. However, partial support for this hypothesis was found, with evidence of a slight negative association between care and psychopathy $(r=-.11, p=.06)$, although the correlation with AMO care failed to reach significance.

The second hypothesis stated that self-promotion scores would be positively correlated with each of the Dark Triad traits. Support for this prediction was found, with strong positive correlations observed between self-promotion and Machiavellianism $(r=.51, p<.001)$, $\operatorname{narcissism}(r=.36, p<.001)$, and psychopathy $(r=.56, p<.001)$.

With respect to the HEXACO personality traits, self-promotion was expected to be negatively correlated with Honesty-Humility and Conscientiousness. This prediction was supported $(r=-.51, p<.001$ and $r=-.38, p<.001$, respectively). In addition, justice scores were expected to be positively correlated with Honesty-Humility and Conscientiousness. Once again, this prediction was supported when justice was measured using both the AMO $(r=.32, p<.001$ and $r=.25, p<.001$, respectively) and the MMO-2 $(r=.27, p<.001$ and $r=.21, p<.001$, respectively).

The last hypothesis predicted that endorsement of a care orientation would be associated with high scores on Agreeableness and Emotionality. As reported in Table 16, this prediction 
was also supported when care was assessed using both the AMO $(r=.13, p<.05$ and $r=.24, p<$ $.001)$ and MMO-2 $(r=.24, p<.001$ and $r=.36, p<.001)$.

\subsection{Discussion}

Following item-level analyses, the AMO was reduced to 34 items (see Appendix C). Each of these items met basic psychometric criteria. The resulting care, justice, and selfpromotion scales demonstrated acceptable levels of internal consistency. The results of the factor analyses revealed that three moral orientation factors emerged in about half of the scenarios. However, for the remaining scenarios, only two factors were extracted, with some items demonstrating high cross-loadings. These results, taken together with the results of the item analyses, suggest that further scale refinement is needed. Additional items should be written, administered to a third sample, and compared to existing items to test for psychometric properties. Ideally these new items should reduce overlap between the dimensions. A detailed discussion of the implications of these findings, as well as the results of the validation analyses will be presented in Chapter 4. 


\section{CHAPTER FOUR: GENERAL DISCUSSION AND CONCLUSIONS}

\subsection{General Discussion}

The goal of the present study was to extend previous research on individual differences in moral orientation by developing and assessing a novel orientation using a self-report measure. This new orientation, termed self-promotion, reflects a tendency to focus on factors that directly impact oneself, and in particular, how one can personally benefit from difficult situations. Individuals who endorse a self-promotion orientation are more concerned with these types of factors than they are with how others are affected or what policies or rules are in effect.

Study 1 described the development of this new scale, the AMO. The format of the AMO was modelled after previous moral orientation scales (Liddell, 2006; Yacker \& Weinberg, 1990), which consist of a series of hypothetical moral dilemmas. Following each dilemma participants were asked to rate the likelihood that various factors would impact their decision. Each item or factor was written to reflect one of the three moral orientations. Individuals received a score on each moral orientation scale by aggregating their responses across all scenarios.

In addition to assessing a novel moral orientation, self-promotion, the AMO differed from previous assessments in a number of ways. In particular, the nature of the scenarios used in the AMO was quite different than those used in existing measures. The MMO-2 contains scenarios that typical university students may encounter, and consequently is recommended for use with student samples (Liddell, 2006). In addition, the MOS contains situations which children are typically exposed to, which one could reasonably argue does not assess how participants reason as adults. Finally, although the MJS uses a broader range of scenarios, the descriptions are rather long and detailed, thereby increasing susceptibility to fatigue effects and limiting the scale's utility (Ackerman \& Kanfer, 2009). 
The AMO attempted to overcome these problems by covering a broad range of topics that would be recognizable to the general population. A list of potential topics was generated by examining online opinion polls and news articles discussing controversial issues (Moral Issues, 2013). From this list, scenarios were generated and rated by graduate students in psychology according to the five moral themes described by MFT (Graham et al., in press). Agreement across these ratings indicated that the scenarios covered a breadth of topics that were perceived as highly controversial in current North American society (e.g., physician assisted suicide), without having excessive religious overtones (e.g., abortion).

Although some researchers suggest using real-life moral dilemmas to increase the external validity of moral orientation assessments (Wark \& Krebs, 1997), these were not used in the present study. Because the goal of the present study was to create a standardized assessment that could be used readily for empirical research, the decision was made to not include real-life dilemmas. To do so would require the researcher to ask participants to generate their own scenarios, and then spend hours coding responses. Such measures are time consuming to administer, complete, and score, thereby limiting their utility for research. As such, although the present study used hypothetical dilemmas, attempts were made to make the scenarios as realistic as possible. The goal was to create scenarios that contained themes the average person may experience in their lifetime in both personal and professional settings (e.g., stopping someone from driving drunk, dealing with a difficult co-worker).

In addition to describing the development of the AMO, Study 1 also analyzed the responses of a sample of undergraduate students to identify potentially problematic items. Although a number of troublesome items were identified, no items were deleted as a result of these analyses due to the nature of the relatively small, gender-biased, student sample. Rather, 
the primary goal of Study 1 was to test for the potential effects of different instruction sets on moral orientation scores. Because some researchers have found that different scenarios can evoke different orientation responses (Haviv \& Leman, 2002) there was also concern that different orientations may be displayed depending on how personal the instructions were (i.e., "How likely is it to impact your final decision", "How likely is it to impact Kelly’s final decision", and "How likely it is to impact your final decision, if you were Kelly"). Surprisingly, the intimateness of instructions had little impact on orientation scores in Study 1. The only significant differences were found for self-promotion scores between those participants in conditions A and B; such that those who received personal scenarios and personal instructions (A) scored lower than those who received impersonal scenarios and impersonal instructions (B). As such, it seems that the instructions had little impact on moral orientation scores. Therefore, the decision was made to only include personal scenarios in the next version of the AMO in an attempt to capture the most realistic responses - those responses that are given when an individual is personally faced with a moral dilemma.

Study 2 administered the personal version of the AMO scale to an online community sample. Based on the data collected a number of problematic items were identified and removed, reducing the scale from 68 to 34 items. The results of a series of EFAs suggested a three factor solution for two of the scenarios, with care, justice, and self-promotion items loading exclusively onto one factor each. For the remaining four scenarios, two factors were extracted based on the results of parallel analysis. For one scenario, a two factor solution was expected because all selfpromotion items were dropped after item analysis. Indeed, the two factors extracted in this scenario clearly reflected care and justice items. However, for the remaining three scenarios the 
results of the EFAs suggested that further item revision is necessary to more clearly delineate between the different moral orientations.

In addition to testing the psychometric properties of the AMO, this study also attempted to provide preliminary evidence of the validity of this novel measure. Evidence of convergent validity for the care and justice subscales of the AMO was observed in both Study 1 and Study 2. Care as assessed by the AMO was found to be significantly positively correlated with care as assessed by the MMO-2. Similarly, AMO justice was significantly correlated with MMO-2 justice. In addition, AMO care and justice scores were significantly associated with one another, as was the case with the MMO-2 care and justice scores.

To examine the construct validity of the AMO, correlations were computed between each moral orientation dimension (assessed by both the AMO and the MMO-2) and the Dark Triad and HEXACO personality traits. First, it was expected that care would be negatively correlated with each of the Dark Triad traits, with psychopathy displaying the strongest association because it is commonly regarded as the most maladaptive of the three traits (Jonason \& Krause, 2013). Counter to predictions, care was found to be positively correlated with Machiavellianism for both the AMO and MMO-2. Although it was not expected that someone who reports deceptive and manipulative tendencies would indicate concern for others, the finding of a weak positive association suggests that these individuals do consider these factors to some extent. However, it may be that the Machiavellian reports concern for others because they know that in order to use people in the future, they need to maintain a certain level of friendship. Jonason and Schmitt (2012) found that individuals who scored high on the Dark Triad tended to form friendships for strategic purposes. This finding lends some support to the notion that if the Machiavellian were 
to completely disregard others' feelings, it is unlikely these individuals will remain present long enough to be useful to them.

The lack of a significant negative association between care and narcissism also contradicted the stated hypothesis. However, given the increasing literature on narcissism being the least antisocial of the Dark Triad traits (Jonason \& Krause, 2013), perhaps the lack of a significant association here is further support for the less dysfunctional nature of this trait. Lastly, psychopathy was found to be negatively associated with AMO care, although the correlation failed to reach significance. The significant negative association between psychopathy and MMO-2 care supports the notion of limited empathy and concern for others associated with psychopathy (Paulhus \& Williams, 2002). However, the lack of a significant association with AMO care suggests that further scale revision may be necessary to ensure the dimension captures adequately the notion of genuine concern for others.

The second hypothesis stated that self-promotion would be positively associated with each of the Dark Triad traits. This prediction was supported, with strong positive correlations observed between self-promotion and each Dark Triad traits. In addition, the strongest association was found with psychopathy; again supporting the conclusion that psychopathy is the “darkest" of these traits (Jonason \& Krause, 2013). These results provide support for the selfpromotion construct proposed in this study, which was described as an orientation that reflected concern primarily for oneself, regardless of the rules or others. However, the lack of a significant negative association between self-promotion and care is unexpected. The results seem to suggest that individuals can simultaneously be concerned for themselves and others, which is counter to the "regardless of others" portion of the operational definition of self-promotion. Efforts to clarify this unexpected finding would benefit from an examination of other personality traits 
associated with self-promotion (e.g., altruistic tendencies, partner-reported relationship satisfaction).

Further evidence of the construct validity of AMO is evident from significant correlations between the moral orientation dimensions and various HEXACO traits. As predicted, selfpromotion was negatively correlated with Honesty-Humility and Conscientiousness. Again this supports the egocentric, manipulative, non-empathetic nature of the self-promotion orientation. Also in line with predictions, justice was found to be positively correlated with HonestyHumility and Conscientiousness, highlighting the distinction between justice and self-promotion. Lastly, care scores were significantly positively associated with Agreeableness and Emotionality, reflecting the concern for others and focus on maintaining relationships. The fact that each of these moral orientations was found to be significantly correlated with the predicted HEXACO traits, in the expected direction, once again provides evidence of construct validity.

In addition to examining associations between moral orientations and existing models of personality, Study 2 also examined sex differences in AMO, MMO-2, Dark Triad, and HEXACO scores. Although previous researchers reported that women scored higher on care, while men scored higher on justice (Donenberg \& Hoffman, 1988; Johnston, 1988), in the present study women were found to score higher on both the care and justice scales of the AMO and MMO-2. The fact that women scored higher than did men on both measures of justice was unexpected, and adds to the conflicting literature on sex differences in moral orientation. Taken with the results of previous researchers (Beal, Garrod, Ruben, Stewart, \& Dekle 1997; Friedman, Robinson, \& Friedman, 1987) it seems evident that there is not a clear "male" (justice) or "female" (care) orientation as Gilligan (1982) proposed. Future researchers may wish to examine how gender identity rather than biological sex is associated with moral orientation. Examining 
this distinction may clarify the disparate findings of sex differences, as studies have shown that in many instances gender identity can predict various behaviours better than sex can (Dinella, Fulcher, \& Weisgram, 2014; Verhofstadt \& Weytens, 2013).

With respect to sex differences in moral orientation, it was expected that men would score higher on the self-promotion scale than women. The difference was expected because men have been found to score consistently higher than women on measures of antisocial personality (Jones \& Paulhus, 2014), and the self-promotion scale was expected to be highly correlated with these maladaptive traits. These predictions were supported, with men scoring significantly higher than women on self-promotion, and each of the Dark Triad traits. These results, along with the significant associations observed between self-promotion and the Dark Triad, lend support to the antisocial nature of this novel moral orientation.

As discussed previously in this paper, existing measures of moral orientation (Liddell, 2006; Yacker \& Weinberg, 1990; Gump et al., 2000) are similar to each other in that they assume normal moral development. That is, they were not written with the intention of assessing “abnormal" or maladaptive orientations. The goal of the present study was to extend these models to include the responses of those individuals who display subclinical, maladaptive personality traits in their daily lives. Working from the care-versus-justice framework, it was difficult to predict how individuals who score high on the Dark Triad would respond in these scenarios. They likely would not score highly on care items, since they tend to report deficits in empathy and remorse for their actions (Jonason, Lyons, Bethell, \& Ross, 2013). Similarly, justice items reflect concern for the law and fairness, which is not typical of these individuals (Giammarco \& Vernon, 2014). The presence of strong negative correlations between each of the Dark Triad traits and justice scores on both the AMO and MMO-2 support this latter assumption. 


\subsection{Limitations}

Despite contributing a number of interesting findings to the moral orientation literature, there are some limitations of the present study that should be considered when interpreting the results. First, although a number of correlations were found in the expected direction, in many instances the nature of these associations was much stronger than expected. For example, Liddell and Davis (1996) reported that care and justice scores on the MMO-2 are typically correlated around $r=.28$. However, in the present study they were found to correlate $r=.67, p<.05$. In addition, Machiavellianism and narcissism are typically found to correlate $r=.17$ to .29 (Lee \& Ashton, 2005; Jones \& Paulhus, 2014), but in Study 2 they were found to correlate $r=.38, p<$ .001. Similarly, narcissism and psychopathy were found to correlate $r=.54, p<.001$, despite previous research finding the typical correlation to be between $r=.31$ to .37 (Lee $\&$ Ashton, 2005; Jones \& Paulhus, 2014). Similar results were obtained for correlations between each of the Dark Triad traits and Conscientiousness.

The fact that unusually high correlations were observed between several variables may suggest some sort of response bias within the online sample used in Study 2. Given that both the Short-D3 and HEXACO-60 contain a number of reverse-keyed items it is unlikely that these results are due to acquiescence. However, the pattern of results may suggest the presence of demand characteristics; with the participants responding in such a way that they believe the experimenter wants them to. As indicated by the correlations reported in Chapter 3, the results may also be influenced by social desirability.

In addition to a potential response bias, the analyses conducted during this study revealed another potential problem - the use of scenarios to measure moral orientation. The scenario test format was selected for the AMO because it is common practice among other assessments of 
moral orientation (Liddell, 2006; Yacker \& Weinberg, 1990). However, as described in Chapter 2, the scenario format was problematic for factor analysis. Performing an EFA on the entire scale, as well as on the established MMO-2 measure, resulted in factors that reflected scenarios rather than the hypothesized dimensions. To overcome this problem the scenarios of the AMO were conceptualized as parallel forms of the same measure. However, to confidently draw this conclusion a number of additional validation studies are needed to ensure that participants respond consistently across scenarios. That is, care, justice, and self-promotion scores should not differ across scenarios. If they do, this would severely challenge the notion of parallel tests. In addition, items within each scenario would need to meet acceptable levels of internal consistency.

These analyses were not conducted in the present study due to the fact that items for the AMO were still under revision. It is difficult to show that scenarios are parallel forms of the same measure when each scenario contains psychometrically flawed items. Rather, attempts to test for parallel form should begin with established, published measures of moral orientation, such as the MMO-2 (Liddell, 2006). This would involve showing that the scenarios of the MMO-2 measure the same constructs, and that if one were to randomly select scenarios from the MMO-2 and administer them to participants, care and justice scores would remain the same. If this were the case, similar analyses would need to be conducted on the AMO.

Alternatively, future researchers may wish to examine the utility of the scenario-based measure of moral orientation versus more traditional personality assessments (e.g., presenting participants with items such as "I like to consider how my actions will impact others before making a decision.", "When in a difficult situation, I tend to follow the rules."). Although such factor analytic issues would likely not be problematic with these traditional formats, they may 
sacrifice some external validity. In addition, the use of these more traditional formats for morality may be more susceptible to social desirability responding than is the case with the commonly used scenarios. Investigations into the utility of scenario-based versus traditional assessments should consider each of these factors.

\subsection{Future Directions}

4.3.1 Scale development. This study was the first to create a self-report measure of moral orientation that included a third orientation, self-promotion. Although preliminary validation evidence was found for this novel measure, further revisions are necessary before the AMO is ready to be used for empirical research. First, additional items should be written and administered along with the existing scale. The goal of this administration should be to retain a sufficient number of items for each scenario (approximately ten per scenario) to capture adequately each of the three orientations. Retained items should meet psychometric criteria similar to those used in Study 2. In addition, to ensure homogeneity within orientations, items that correlate highly with other dimensions should be removed.

Once a psychometrically sound item pool has been created for the AMO, a confirmatory factor analysis (CFA) should be conducted on an independent sample. Conducting a CFA on the AMO will allow for various fit indices to test whether or not the proposed three factor solution fits the data appropriately (Kenny, 2014). In addition, the fit of this three factor model should be compared to other models (i.e., two factor, one factor, etc.) to determine if the three factor structure is the most parsimonious, well fitting model.

The present study used the Classical Test Theory (CTT; Kline, 2005) approach to scale development to create the AMO. Arguably this is the most common practice for psychological test development (Kline, 2005). However, Item Response Analysis (IRT) has gained 
considerable attention in recent years (Robie, Zickar, Schmit, 2001; Sliter \& Zickar, 2014). An IRT approach to test construction frames item responses as observable measures of an individual's underlying level (or ability) on some latent trait. As such, rather than considering all items to be equal (as CTT does), IRT allows for some items to be "more difficult" than others. In terms of personality, a "more difficult" item would be one that requires the respondent to have a greater level of the underlying latent trait in order to endorse the item. For this reason, it has been argued that IRT can allow the researcher to make finer measurement distinctions at the extreme levels of the latent trait. This also means that some items that may be discarded under CTT guidelines (i.e., due to low variability) may be deemed acceptable and even desired items according to IRT principles because they distinguish between individuals with different levels of the measured trait (Rudner, 2001). As such, future development and modifications to the AMO would benefit greatly from the inclusion of IRT analysis.

4.3.2 Computer Adaptive Testing. In addition to IRT, another area of test development that is receiving attention is Computer Adaptive Testing (CAT; Forbey, Ben-Porath, 2007; Hol, Vorst, Mellenbergh, 2008). With the majority of personality tests being administered online and over the computer, researchers have begun studying the benefits of CAT for personality scales. CAT takes into account how a participant is responding to test items and adjusts the remainder of the test based on these responses (Meijer \& Nering, 1999).

An example of CAT outside of personality is the Graduate Record Exam (GRE). Participants answer a series of math questions. If they get a particular question wrong, the next question they get is easier, and if they get it right, the next question is harder. Adapting the test to an individual participant's responses in this way allows the researcher to only present participants with items that are relevant to them. So, if a participant responds consistently to a 
few items that measure the same construct (e.g., love of reading), little information is gained by continuing to ask them these types of questions because they keep giving the same answer. But, when a participant varies their answers (I don't like reading poems, I do like reading books, I don't like fiction books, I do like biographies) CAT allows for additional items to be presented on that topic so the experimenter can distinguish what it is about reading the person likes and does not like.

This is perhaps the greatest benefit to CAT - the ability to make more refined measurements. Not only can CAT offer more refined measurement, it can considerably shorten the time of test administration (Hol et al., 2008), which in turn may limit fatigue effects, boredom, and careless responding. It seems that the use of CAT for moral orientation research would be particularly helpful, because the scenario-based nature of these assessments would benefit from a shorter administration time.

4.3.3. Moral orientation in the workplace. Once a psychometrically sound and validated version of the AMO has been developed there are numerous uses for a measure of moral orientation that assesses both normal and "abnormal" morality. One particularly fruitful area of investigation could be moral decision making in the workplace. A number of industrial and organizational (I/O) psychology papers have recently been published exploring the use of personality traits to predict counterproductive work behaviours (CWBs; Bowling \& Eschleman, 2010; Jensen \& Patel, 2011). CWBs can include many behaviours, such as showing up late to work, calling in sick when you are not actually ill, stealing office supplies, and stonewalling fellow co-workers. Interestingly, research has shown that maladaptive personality traits may predict engagement in CWBs better than is the case with more traditional personality traits $(\mathrm{Wu}$ \& Lebreton, 2011). 
Based on these findings, it would be interesting to examine if and/or how moral orientation would be associated with such behaviours. Gaining insight into how individuals approach morals dilemmas seems particularly relevant within a workplace context given that business professionals, especially leaders, are often in difficult ethical situations, as evident from the overwhelming body of literature on business ethics (Dzuranin, Shortridge, \& Smith, 2013; Quick \& Goolsby, 2013). In these settings, the decisions made not only affect the individual personally and professionally, but also impact the employees, the company's bottom line, and the company’s public image.

\subsection{Conclusion}

The goal of this study was to expand upon previous assessments of moral orientation to include a novel dimension, self-promotion. This new self-promotion orientation was intended to capture the responses of those individuals who are less concerned with others or the rules and most concerned about themselves when it comes to moral dilemmas. After developing and administering the AMO to two independent samples, evidence of this proposed self-promotion orientation emerged. Although additional revisions to the AMO are necessary, preliminary validation evidence supports the notion of self-promotion as a more socially malevolent approach to morality. 


\section{References}

Ackerman, P.L., \& Kanfer, R. (2009). Test length and cognitive fatigue: An empirical examination of effects on performance and test-taker reactions. Journal of Experimental Psychology: Applied, 15, 163-181. doi: 10.1037/10015719

Anwar, N., Bhutto, N.A., Maitlo, Q., \& Khawaja, H.A. (2012). The impact of gender role and personality on moral orientation. Interdisciplinary Journal of Contemporary Research in Business, 3, 731-737.

Ashton, M.C., \& Lee, K. (2009). The HEXACO-60: A short measure of the major dimensions of personality, Journal of Personality Assessment, 91, 340-345. doi: $10.1080 / 00223890902935878$

Bartek, S.E., Krebs, D.L., \& Taylor, M.C. (1993). Coping, defending, and the relations between moral judgment and moral behavior in prostitutes and other female juvenile delinquents. Journal of Abnormal Psychology, 102, 66-73. doi:10.1037/0021-843X.102.1.66

Bartels, D.M., \& Pizarro, D.A. (2011). The mismeasure of morals: Antisocial personality traits predict utilitarian responses to moral dilemmas. Cognition, 121, 154-161. doi: 10.1016/j.cognition.2011.05.010

Beal, C.R., Garrod, A., Ruben, K., Stewart, T.L., \& Dekle, D.J. (1997). Children's moral orientation: Does the gender of dilemma character make a difference. Journal of Moral Education, 26, 45-58. doi: 10.1080/0305724970260103

Bowling, N.A., \& Eschleman, K.J. (2010). Employee personality as a moderator of the relationships between work stressors and counterproductive work behavior. Journal of Occupational Health and Psychology, 15, 91-103. doi: 10.1037//a0017326 
Bruess, B.J., \& Pearson, F.C. (2002). The debate continues: Are there gender differences in moral reasoning as defined by Kohlberg? College Student Affairs Journal, 21, 38-52. Retrieved from http://eric.ed.gov/?id=EJ650150

Bush, A.J., Krebs, D.L., \& Carpendale, J.I. (1993). The structural consistency of moral judgments about AIDS. Journal of Genetic Psychology: Research and Theory on Human Development, 154, 167-175. doi: 10.1080/00221325.1993.9914730

Campbell, J., Schermer, J.A., Villani, V.C., Nguyen, B., Vickers, L., \& Vernon, P.A. (2009). A behavioral genetic study of the Dark Triad of personality and moral development. Twin Research and Human Genetics, 12, 132-136.

Christie, R., \& Geis, F.L. (1970). Studies in machiavellianism. New York, NY: Academic Press. Colby, A., \& Damon, W. (1983). Listening to a different voice: A review of Gilligan's “In a different voice". Merrill-Palmer Quarterly, 29, 473-481.

Comrey, A.L. (1983). An evaluation of they Myers-Briggs Type Indicator. Academic Psychology Bulletin, 5, 115-129.

Costa, P.T., Jr., \& McCrae, R.R. (1992). NEO-PI-R Professional Manual-Revised NEO Personality Inventory (NEO-PIR) and NEO Five-Factor Inventory (NEO-FFI). Odessa, FL: Psychological Assessment Resources.

Crain, W.C. (1985). Kohlberg's stages of moral development. In Theories of Development (pp. 118-136). Englewood Cliffs, NJ: Prentice-Hall.

Crandall, C.S., Tsang, J., Goldman, S., \& Pennington, J.T. (1999). Newsworthy moral dilemmas: Justice, caring, and gender. Sex Roles, 40, 187-209. Retrieved from http://journals2.scholarsportal.info.proxy1.lib.uwo.ca/details/03600025/v40i34/187_nmdjcag.xml 
Dawson, T.L. (2002). New tools, new insights: Kohlberg's moral judgement stages revisited. International Journal of Behvioral Development, 26, 154-166. doi: $10.1080 / 01650250042000645$

Dinella, L.M., Fulcher, M., \& Weisgram, E.S. (2014). Sex-typed personality traits and gender identity as predictors of young adults' career interests. Archives of Sexual Behavior, 43, 493-504. doi: 10.1007/s10508-013-0234-6

Donenberg, G.R., \& Hoffman, L.W. (1988). Gender differences in moral development. Sex Roles, 18, 701-717. doi: 10.1007/BF00288055

Dozois, D.J.A., Dobson, K.S., \& Ahnberg, J.L. (1998). A psychometric evaluation of the Beck Depression Inventory -II. Psychological Assessments, 10, 83-89. doi: 10.1037/10403590.10 .2 .83

Dzuranin, A.C., Shortridge, R.T., \& Smith, P.A. (2013). Building ethical leaders: A way to integrate and assess ethics education. Journal of Business Ethics, 115, 101-114. doi: $10.1007 / \mathrm{s} 10551-012-1371-\mathrm{X}$

Fabrigar, L.R., Wegener, D.T., MacCallum, R.C., \& Strahan, E.J. (1999). Evaluating the use of exploratory factor analysis in psychological research. Psychological Methods, 4, 272 299. doi:10.1037/1082-989X.4.3.272

Forbey, J.D., \& Ben-Porath, Y.S. (2007). Computerized adaptive personality testing: A review and illustration with the MMPI-2 computerized adaptive version. Psychological Assessment, 19, 14-24. doi: 10.1037//1040-3590.19.1.14

Friedman, W.J., Robinson, A.B., \& Friedman, B.L. (1987). Sex differences in moral judgments? A test of Gilligan's theory. Psychology of Women Quarterly, 11, 37-46. doi: 10.1111/j.1471-6402.1987.tb00772.x 
Gao, Y., \& Tang, S. (2013). Psychopathic personality and utilitarian moral judgment in college students. Journal of Criminal Justice, 41, 342-349. doi: 10.1016/j.jcrimjus.2013.06.012

Garwood, G.S., Levine, D.W., \& Ewing, L. (1980). Effect of protagonist's sex on assessing gender differences in moral reasoning. Developmental Psychology, 16, 677-678. doi: $10.1037 / 0012-1649.16 .6 .677$

Gaughan, E.T., Miller, J.D., \& Lynam, D.R. (2012). Examining the utility of general models of personality in the study of psychopathy: A comparison of the HEXACO-PI-R and NEO PI-R. Journal of Personality Disorders, 26, 513-523. doi: 10.1521/pedi.2012.26.4.513

Gert, B. (2011). The definition of morality. The Stanford encyclopedia of philosophy (Spring 2011 ed.). Retrieved from http://plato.stanford.edu/entries/morality-definition/

Giammarco, E.A., \& Vernon, P.A. (2014). Vengeance and the Dark Triad: The role of empathy and perspective taking in trait forgivingness. Personality and Individual Differences, 67, 23-29. doi: 10.1016/j.paid.2014.02.010

Gilligan, C. (1982). New maps of development: New visions of maturity. American Journal of Orthopsychiatry, 52, 199-212. doi: 10.1111/j.1939-0025.1982.tb02682.x

Glenn, A.L., Koleva, S., Iyer, R., Graham, J., \& Ditto, P.H. (2010). Moral identity in psychopathy. Judgment and Decision Making, 5, 497-505.

Glover, R.J. (2001). Discriminators of moral orientation: Gender role or personality? Journal of Adult Development, 8, 1-7.

Gump, L.S., Baker, R.C., \& Roll, S. (2000). The moral justification scale: Reliability and validity of a new measure of care and justice orientations. Adolescence, 35, 67-76. 
Graham, J., Haidt, J., Koleva, S., Motyl, M., Iyer, R., Wojcik, S.P., \& Ditto, P.H. (in press). Moral Foundations Theory: The pragmatic validity of moral pluralism. Advances in Experimental Social Psychology. Retrieved from http://www-bcf.usc.edu/ jessegra/papers/GHKMIWD.inpress.MFT.AESP.pdf

Hare, R.D. (1985). Comparison of procedures for the assessment of psychopathy. Journal of Consulting and Clinical Psychology, 53, 7-16. doi: 10.1037/0022-006X.53.1.7

Haslam, N. (2011). The latent structure of personality and psychopathology: A review of trends in taxometric research. Scientific Review of Mental Health Practices, 8, 17-29.

Haviv, S., \& Leman, P.J. (2002). Moral decision-making in real life: Factors affecting moral orientation and behaviour justification. Journal of Moral Education, 31, 121-140. doi: $10.1080 / 03057240220143241$

Henrysson, S. (1963). Correction of item-total correlations in item analysis. Psychometrika, 28, 211-218.

Hol, A.M., Vorst, H.C.M., Mellenbergh, G.J. (2008). Computerized adaptive testing of personality traits. Journal of Psychology, 216, 12-21. doi: 10.1027/0044-3409.216.1.12

Holstein, C.B. (1976). Irreversible, stepwise sequence in the development of moral judgment: A longitudinal study of males and females. Child Development, 47, 51-61. doi: $10.2307 / 1128282$

Jackson, D.N. (1970). A sequential system for personality scale development. In C.D. Speilberger (Ed.), Current topics in clinical and community psychology (Vol. 2, pp. 6196). New York: Academic Press.

Jaffee, S., \& Hyde, J.S. (2000). Gender differences in moral orientation: A meta-analysis. Psychological Bulletin, 126, 703-726. doi: 10.1037/0033-2909.126.5.703 
Jensen, J.M., \& Patel, P.C. (2011). Predicting counterproductive work behavior from the interaction of personality traits. Personality and Individual Differences, 51, 466-471. doi: 10.1016/j.paid.2011.04.016

Johnson, J.A. (2005). Ascertaining the validity of individual protocols from web-based personality inventories. Journal of Research in Personality, 39, 103-129. doi: 10.1016/j.jrp.2004.09.009

Johnston, D.K. (1988) Adolescents' solutions to dilemmas in fables: Two moral orientations two problem solving strategies. In C. Gilligan, J. Ward, J. Mclean Taylor, \& B.Bardige (Eds.), Mapping the moral domain (pp. 49-71). Cambridge: Harvard University Press.

Jonason, P.K., \& Krause, L. (2013). The emotional deficits associated with the Dark Triad traits: Cognitive empathy, affective empathy, and alexithymia. Personality and Individual Differences, 55, 532-537. doi: 10.1016/j.paid.2013.04.027

Jonason, P.K., Lyons, M., Bethell, E.J., \& Ross, R. (2013). Different routes to limited empathy in the sexes: Examining the links between the Dark Triad and empathy. Personality and Individual Differences, 54, 572-576. doi: 10.1016/j.paid.2012.11.009

Jonason, P.K., \& McCain, J. (2012). Using the HEXACO model to test the validity of the Dirt Dozen measure of the Dark Triad. Personality and Individual Differences, 53, 935-938. doi: 10.1016/j.paid.2012.07.010

Jonason, P.K., \& Schmitt, D.P. (2012). What have you done for me lately? Friendship-selection in the shadow of the Dark Triad traits. Evolutionary Psychology, 10, 400-421. Retrieved from http://europepmc.org/abstract/MED/22947669

Jones, D.N., \& Paulhus, D.L. (2014). Introducing the Short Dark Triad (SD3): A brief measure of dark personality traits. Assessment, 21, 28-41. doi: 10.1177/1073191113514105 
Kay, S.R. (1982). Kohlberg's theory of moral development: Critical analysis of validation studies with the defining issues test. International Journal of Psychology, 17, 27-42.

Kenny, D.A. (2014, February 6). Measuring model fit. Retrieved from http://davidakenny.net/cm/fit.htm

Kline, P. (1979). Psychometrics and psychology. London: Academic Press.

Kline, P. (2000). The handbook of psychological testing ( $2^{\text {nd }}$ Edition). London: Routledge

Kline, T.J.B. (2005). Classical test theory: Assumptions, equations, limitations, and item analyses. In Psychological testing: A practical approach to design and evaluation (pp. 91-106). California: Sage Publications.

Koenigs, M., Kruepke, M., Zeier, J., \& Newman, J.P. (2012). Utilitarian moral judgment in psychopathy. Social Cognitive and Affective Neuroscience, 7, 708-714. doi: $10.1093 / \mathrm{scan} / \mathrm{nsr} 048$

Kohlberg, L. (1958). The development of modes of moral thinking and choice in the years 10 to 16 (Doctoral thesis). University of Chicago: Chicago.

Kurtines, W., \& Grief, E.B. (1974). The development of moral though: Review and evaluation of Kohlberg's approach. Psychological Bulletin, 81, 453-470. doi: 10.1037/h0036879

Lee, K., \& Ashton, M.C. (2004). Psychometric properties of the HEXACO Personality Inventory. Multivariate Behavioral Research, 39, 329-358. doi: 10.1207/s15327906 mbr3902_8

Lee, K., \& Ashton, M.C. (2005). Psychopathy, Machiavellianism, and narcissism in the FiveFactor Model and the HEXACO model of personality structure. Personality and Individual Differences, 38, 1571-1582. doi: 10.1016/j.paid.2004.09.016 
Lee, K., \& Ashton, M.C. (2014). The Dark Triad, the Big Five, and the HEXACO model. Personality and Individual Differences, 67, 2-5. doi: 10.1016/j.paid.2014.01.048

Liddell, D.L. (2006). The measure of moral orientation [Testing Manual].

Liddell, D.L., \& Davis, T.L. (1996). The measure of moral orientation: Reliability and validity evidence. Journal of College Student Development, 37, 485-493.

Liddell, D.L., Halpin, G., \& Halpin, W.G. (1992). The measure of moral orientation: Measuring the ethics of care and justice. Journal of College Student Development, 33, 325-330.

Lifton, P.D. (1985). Individual differences in moral development: The relation of sex, gender, and personality to morality. Journal of Personality, 53, 306-334. doi: 10.111/j.14676494.1985.tb00368.x

Martin, R.M., Shaftro, M., \& Van Deinse, W. (1977). The reliability, validity, and design of the Defining Issues Test. Developmental Psychology, 13, 460-468. doi: 10.1037/00121649.13.5.460

Maqsud, M. (1998). Moral orientation of Batswana high school pupils in South Africa. The Journal of Social Psychology, 138, 255-257. doi: 10.1080/00224549809600377

McCrae, R.R., \& Costa, P.T.,Jr., (1989). Reinterpreting the Myers-Briggs Type Indicator from the perspective of the Five-Factor Model of personality. Journal of Personality, 57, 1740. doi:10.1111/1467-6494.ep8972588

McCrae, R.R., \& Costa, P.T.,Jr., (1997). Personality trait structure as a human universal, American Psychologist, 52, 509-516. doi: 10.1037/0003-066X.52.5.509

Meade, A.W., \& Craig, S.B. (2012). Identifying careless response in survey data. Psychological Methods, 17, 437-455. doi: 10.1037/a0028085 
Meijer, R.R., \& Nering, M.L. (1999). Computerized adaptive testing: Overview and introduction. Applied Psychological Measurement, 23, 187-194. doi: 10.1177/01466219922031310

Moral Issues (2013). Gallup Poll. Retrieved from http://www.gallup.com/poll/1681/MoralIssues.aspx?utm_source=email-a-friend\&utm_medium=email\&utm_campaign= sharing\&utm_content=morelink\#1

Muthukrishna, N., \& Govender, D. (2011). Moral reasoning in the early years: Age and gender patterns amongst young children in South Africa. Gender and Behaviour, 9, 3624-3641.

Myers, I.B., \& McCaulley, M.H. (1985). Manual: A guide to the development and use of the Myers-Briggs Type Indicator. Palo Alto: Consulting Psychologists Press.

Niemczynski, A., Czyzowska, D., Pourkos, M., \& Mirski, A. (1988). The Cracow study with Kohlberg's Moral Judgment Interview: data pertaining to the assumption of cross-cultural validity. Polis Psychological Bulletin, 19, 43-53.

O’Connor, B.P. (2000). SPSS and SAS programs for determining the number of components using parallel analysis and Veciler's MAP test. Behavior Research Methods, Instrumentation, and Computers, 32, 396-402.

Ones, D.S., \& Viswesvaran, C. (1996). Bandwidth-fidelity dilemma in personality measurement for personnel selection. Journal of Organizational Behavior, 17, 609-626. doi: 10.1 002/(SICI)1099-1379(199611)17:6<609::AID-JOB1828>3.0.CO;2-K

Paulhus, D.L. (1991). Measurement and control of response bias. In J.P. Robinson, P.R. Shaver \& L.S. Wrightsman (Eds.), Measures of personality and social psychological attitudes (pp. 17-59). San Diego, CA: Academic Press. 
Paulhus, D.L., \& Williams, K.M. (2002). The Dark Triad of personality: Narcissism, Machiavellianism, and psychopathy. Journal of Research in Personality. 36, 556-563. doi: 10.1016/S0092-6566(02)00505-6

Paunonen, S.V., \& Jackson, D.N. (2000). What is beyond the Big Five? Plenty! Journal of Personality, 68, 821-835. doi: 10.1111/1467-6494.00117

Pittenger, D.J. (1993). The utility of the Myers-Briggs Type indicator. Review of Educational Research, 63, 467-488. doi: 10.2307/1170497

Pratt, M.W., Golding, G., Hunter, W., Sampson, R. (1988). Sex differences in adult moral orientations. Journal of Personality, 56, 373-391. doi: 10.1111/j.14676494.1988.tb00891.x

Quick, J.C., \& Goolsby, J.L. (2013). Integrity first: Ethics for leaders and followers. Organizational Dynamics, 42, 1-7. doi: 10.1016/j.orgdyn.2012.12.001

Raskin, D.C., \& Hall, C.S. (1981). The narcissistic personality inventory: Alternative form reliability and further evidence of construct validity. Journal of Personality Assessment, 45, 159-162. doi: 10.1207/s15327752jpa4502_10

Rest, J.R. (1979). Development in judging moral issues. Minneapolis: University of Minnesota Press.

Rest, J., Cooper, D., Coder, R., Masanz, J., Anderson, D. (1974). Judging the important issues in moral dilemmas: An objective measure of development. Developmental Psychology, 10, 491-501. doi: 10.1037/h0036598

Rest, J.R., Davison, M.L., \& Robbins, S. (1978). Age trends in judging moral issues: A review of cross-sectional, longitudinal, and sequential studies of the Defining Issues Test. Child Development, 49, 263-279. doi: 10.1111/1467-8624.ep10402731 
Robie, C., Zickar, M.J., \& Schmit, M.J. (2001). Measurement equivalence between applicant and incumbent groups: an IRT analysis of personality scales. Human Performance, 14, 187207. doi: 10.1207/S15327043HUP1402_04

Rothbart, M.K., Hanley, D., \& Albert, M. (1986). Gender differences in moral reasoning. Sex Roles, 15, 645-653. doi: 10.1007/BF00288220

Rudner, L.M. (2001, December). Item response theory. Retrieved from http://echo.edres.org:8080/irt/

Saucier, G., \& Goldberg, L.R. (1998). What is beyond the Big Five? Journal of Personality, 66, 495-524. doi: 10.1111/1467-6494.t01-1-00022

Sliter, K.A., Zickar, M.J. (2014). An IRT examination of the psychometric functioning of negatively worded personality items. Educational and Psychological Measurement, 74, 214-226. doi: 10.1177/0013164413504584

Statistics Canada (2011). National House Survey Profile. Retrieved from http://www12.statcan .gc.ca/nhs-enm/2011/dp-pd/prof/details/page.cfm?Lang=E\&Geo1=PR\& Code1 $=01 \&$ Data $=$ Count $\&$ SearchText $=01 \&$ SearchType $=$ Begins $\&$ SearchPR $=01$ $\& \mathrm{~A} 1=\mathrm{A} 11 \& \mathrm{~B} 1=\mathrm{A} 11 \&$ Custom $=\& \mathrm{TABID}=3$

Taylor, B.W. (1978). Relationship between level of moral development and factual learning in situations with moral overtones. Psychological Reports, 42, 243-253. doi: 10.2466/ $\operatorname{pr} 0 / 1978.42 .1 .243$

Thoma, S.J. (1986). Estimating gender differences in the comprehension and preference of moral issues. Developmental Review, 6, 165-180.

Thoma, S.J. (1989). Standardizing the measurement of moral judgments. PsycCRITIQUES, 34, 533-535. doi: 10.1037/031135 
Turiel, E. (1966). An experimental test of the sequentiality of developmental stages in the child's moral judgments. Journal of Personality and Social Psychology, 3, 611-618. doi: $10.1037 / \mathrm{h} 0023280$

Vacha-Haase, T., \& Thompson, B. (2002). Alternative ways of measuring counselees' Jungian psychological-type preferences. Journal of Counseling \& Development, 80, 173-179. doi: 10.1002/j.1556-6678.2002.tb00180.x

Verhofstadt, L.L., \& Weytens, F. (2013). Biological sex and gender role identity as predictors of spousal support provision: a scenario-based study. Journal of Gender Studies, 22, 166177. doi: 10.1080/09589236.2012.745683

Veselka, L., Schermer, J.A., \& Vernon, P.A. (2012). The Dark Triad and an expanded framework of personality. Personality and Individual Differences, 53, 417-425. doi: 10.1016/j.paid.2012.01.002

Walker, L.J. (1984). Sex differences in the development of moral reasoning: A critical review. Child Development, 55, 677-691. doi: 10.2307/1130121

Walker, L.J., de Vries, B., \& Trevethan, S.D. (1987). Moral stages and moral orientations in reallife and hypothetical dilemmas. Child Development, 58, 842-858. Retrieved from www.jstor.org/stable/1130221

Wark, G.R., \& Krebs, D.L. (1997). Sources of variation in moral judgment: Toward a model of real-life morality. Journal of Adult Development, 4, 163-178. doi:10.1007/BF02510595

Wark, G.R., \& Krebs, D.L. (2000). The construction of moral dilemmas in everyday life. Journal of Moral Education, 29, 5-21. doi: 10.1080/030572400102907 
Weinberg, S.L., Yacker, N.L., Orenstein, S.H., \& DeSarbo, W. (1993). Care and justice moral reasoning: A multidimensional scaling approach. Multivariate Behavioral Research, 28, 435-465. doi: 10.1207/s15327906mbr2804_3

White, R.D. (1999). Are women more ethical? Recent findings on the effects of gender upon moral development. Journal of Public Administration Research and Theory, 9, 459-471. doi: $10.2307 / 1181652$

Wu, J., \& Lebreton, J.M. (2011). Reconsidering the dispositional basis of counterproductive work behavior: The role of aberrant personality. Personnel Psychology, 64, 593-626. doi: 10.1111/j.1744-6570.2011.01220.x

Yacker, N., \& Weinberg, S.L. (1990). Care and justice moral orientation: A scale for its assessment. Journal of Personality Assessment, 55, 18-27. 


\author{
APPENDIX A \\ Personal and Impersonal Versions of the AMO (Study 1)
}

\title{
Personal Scenarios
}

Instructions [Condition A]: Below are a number of factors that may come to mind when trying to make a decision. For each factor, please rate how likely it is to impact your final decision (regardless of what that decision is).

\section{Scenario 1: Student/Teacher Relationships}

You are out with your friends celebrating the end of summer and will soon be returning to school. While having a few drinks at a local bar, you are approached by an attractive individual. You begin talking and find you have an immediate connection. At the end of the night you exchange numbers and begin dating.

When your classes begin, you discover that your partner is the teacher for one of your classes. While you knew that they worked at your school, they were told they would be teaching a different class, but were switched last minute. It is against school policy for teachers and students to date. You must decide whether or not you will continue dating your teacher.

$\underline{\text { Care }}$

1. If we really like each other, we should do what is best for our relationship.

4. I would not want to hurt my partner.

7. My reputation with my classmates could be in jeopardy if they became aware of my relationship.

10. I would feel guilty if my partner lost his/her job because of our relationship.

$\underline{\text { Justice }}$

2. My teacher has a responsibility to report his/her relationship with me to the school.

5. I would feel uncomfortable violating school policy.

8. This is really about conflicting rights: our right to do what we want, and the rights of other students in the class to be treated fairly.

11. I think school policies are put in place for situations exactly like this one.

\section{$\underline{\text { Self-Promotion }}$}

3. I could use this opportunity to boost my average for graduation.

6. Breaking school policy could threaten my graduation.

9. I need to forget about others and think about what is best for me.

13. If I end the relationship, my partner may be angry and purposely give me low grades.

Reading Check

12. We have not broken any rules 


\section{Scenario 2: Refugees with Health Problems}

You are a government case worker and your job is to read immigration applications. After reading all files you must pass only those files that are approved for entry into your country to your boss. Civil wars have devastated parts of the world and thousands of people are leaving their homes, hoping to enter your country. Unfortunately many people are very ill and will require extended medical care. Your government's policy is to accept healthy applicants first, but you know that the sick applicants are in more dangerous situations. You must decide whether or not to let in the healthy applicants first.

\section{Care}

14. There are situations where following policy isn't the best choice.

17. I would focus on giving help where it is needed most.

20. Showing compassion is more important than following the rules.

\section{$\underline{\text { Justice }}$}

15. I would be objective when making my decisions.

18. It is important to always follow policy.

21. I cannot let emotions cloud my judgment.

\section{Self-Promotion}

16. If I do not follow my government's policy, I could be fired.

19. I do not personally benefit from helping the sick applicants, so why bother?

23. I will only get ahead in my career if I follow the rules.

\section{$\underline{\text { Reading Check }}$}

22. It is my job to use my judgment and do what I think is best. 


\section{Scenario 3: Drunk Driving}

You have been a police officer for 15 years in a large city. One night while working you notice a car driving outside its lane and think the driver may be drunk. You pull the car over and see your uncle is the driver. You ask him to complete a sobriety test. Your uncle fails the test but is very polite and apologetic. You know that your uncle does not usually drink, and he admits to you that he is coming from a dinner where he had a few drinks. You know that driving is a large part of your uncle's job and if he receives a ticket he will be unable to work. The roads are empty at this late hour and your uncle is a short 5 minute drive from his home. You must decide whether or not to arrest your uncle.

Care

24. My primary concern is my uncle's safety.

27. My uncle's financial livelihood is at risk.

30. The late hour and empty roads make it less likely my uncle will have an accident.

33. Innocent people could be hurt if my uncle drives home.

$\underline{\text { Justice }}$

25. Driving while impaired is extremely dangerous.

28. I should treat my uncle the same as any other offender.

31. There are no excuses for allowing someone to drive drunk.

34. I should be objective.

Self-Promotion

26. I should not do anything that could jeopardize my own job.

29. It is not my responsibility to clean up the mistakes of other people.

32. If I make exceptions for people, I will never get ahead in my career.

36. If I do my uncle a favour, I should get something in return.

Reading Check

35. My uncle is an alcoholic and needs help. 


\section{Scenario 4: Cheating}

You and your close friend Jessie both work for the same company. Jessie has been dating Alex for the past three years, and you recently started dating Alex's friend, Jamie. The four of you have all become close friends and spend most of your time together. Jessie recently told you that he/she plans to propose to Alex.

One weekend you and Jessie are asked to attend a work conference out of town. You both make plans to attend the conference, but at the last minute you must cancel your trip. Early Saturday morning, you walk to the local coffee shop. On your way you see Alex coming out of an unfamiliar house. Alex is followed someone holding their hand. Before Alex leaves, the person kisses Alex passionately. You duck into a nearby store to avoid being seen by Alex. You must decide whether or not to tell Jessie what you saw.

\section{$\underline{\text { Care }}$}

37. The most important thing is for Jessie not to be hurt.

40. I would not cause harm to someone else's relationship.

43. If Alex is cheating on Jessie, their relationship must not be as happy as I thought.

46. My decision will have an impact on all four of us being friends.

Justice

38. Jessie has a right to know that Alex is cheating.

41. Regardless of Alex's reasons, the rules of his/her relationship with Jessie have been violated.

44. Alex should be held accountable for his/her actions.

48. Under no circumstances is it acceptable for someone to cheat in a relationship.

\section{$\underline{\text { Self-Promotion }}$}

39. I could damage my own relationship with Jamie.

42. If I tell Jessie the truth, he/she may become angry at me and choose to believe Alex instead.

45. I could keep this information to myself and use it against Alex when it is most beneficial for me.

$\underline{\text { Reading Check }}$

47. Jessie and Alex are not in a serious relationship. 


\section{Scenario 5: Assisted Suicide}

Your grandmother has been fighting lung cancer for years. She has tried many treatments, but the cancer continues to return. Recently, she has decided to stop treatment and allow her disease to run its course. One night, while visiting your grandmother in the hospital, she tells you that she is in a great deal of pain and is having difficulty breathing. She says that she would like to end her suffering by taking her own life, but she needs your help. You need to make a decision about whether or not to help.

$\underline{\text { Care }}$

49. It would greatly upset me to see my grandmother in pain.

52. I could threaten my relationships with the rest of my family.

55. If our roles were reversed, I would hope my grandmother would consider my wishes.

58. In some cases, letting someone suffer is worse than helping them die.

Justice

50. I believe helping anyone commit suicide is morally wrong.

53. It is never okay to help someone end their life.

56. I have a responsibility to tell my grandmother's doctor of her intentions.

59. I believe my grandmother has the right to make her own decisions about her health care, within the limits of the law.

\section{Self-Promotion}

51. I could get into serious trouble.

54. My grandmother's death is certain, and I could use the inheritance money sooner rather than later.

57. The risk of being caught is too high.

61. This is not my problem to solve.

$\underline{\text { Reading Check }}$

60. My grandmother's current treatment could cure her cancer. 


\section{Scenario 6: Plagiarism}

You are a student working at a news company. One day you hope to be a journalist. Upset that you have worked for the company for a year and have not written anything, you decide to write a story on your own. You work on the story for weeks, until you are very proud of the final draft. You show the article to your boss, Glen, who reads the article. Glen praises you on your work ethic, but he does not think the article is good enough to be on the website.

The next week you are reading the company's website, when you see your article on the homepage. You are excited until you notice the first author is your supervisor Glen, while you are listed second. The editor congratulates Glen on his work. The editor tells you that if you stay with Glen you will learn everything you need to know about the business. You must decide whether or not to confront Glen.

\section{$\underline{\text { Care }}$}

62. I could threaten my relationship with Glen.

65. I have a right to be hurt my Glen's actions, but I should also show respect for my superior.

68. I am a student and still learning from Glen.

71. Glen is the professional, and without him I would not have anything published.

Justice

63. Regardless of the consequences, the editor should be made aware of the truth.

66. Plagiarism is a serious offence for a journalist and Glen should be punished.

69. Copying another person's work is never acceptable.

72. Under no circumstances is it acceptable to take credit for another person's work.

\section{$\underline{\text { Self-Promotion }}$}

64. I wrote the article and deserve all the credit.

67. I will only get ahead in my career if I stand up for myself.

70. I should do what is best for my career in the long-term.

74. It is okay for me to do what is best for me.

\section{$\underline{\text { Reading Check }}$}

73. Glen wrote the article too, so he has done nothing wrong. 


\section{Impersonal Scenarios}

Instructions [Condition B]: Below are a number of factors that may come to mind when trying to make a decision. For each factor, please rate how likely you think it is to impact XXXX's final decision (regardless of what that decision is). Please make your ratings based on how you think $X X X$ would respond, even if this is different from how you would respond.

Instructions [Condition C]: Below are a number of factors that may come to mind when trying to make a decision. For each factor, please rate how likely it is to impact your final decision, if you were XXXX (regardless of what that decision is).

\section{Scenario 1: Student/Teacher Relationships}

Kelly is out with her friends celebrating the end of summer and will soon be returning to school. While having a few drinks at a local bar, Kelly is approached by an attractive man named James. They begin talking and find they have an immediate connection. At the end of the night Kelly and James exchange numbers and begin dating.

When Kelly's classes begin, she discovers that James is the teacher for one of her classes. While Kelly knew that James worked at her school, he was told he would be teaching a different class, but was switched last minute. It is against school policy for teachers and students to date. Kelly must decide whether or not she will continue dating her teacher.

\section{$\underline{\text { Care }}$}

1. If Kelly and James really like each other, they should do what is best for their relationship.

4. Kelly would not want to hurt James.

7. Kelly's reputation with her classmates could be in jeopardy if they became aware of her relationship.

10. Kelly would feel guilty if James lost his job because of their relationship.

$\underline{\text { Justice }}$

2. James has a responsibility to report his relationship with Kelly to the school.

5. Kelly would feel uncomfortable violating school policy.

8. This is really about conflicting rights: their right to do what they want, and the rights of other students in the class to be treated fairly.

11. School policies are put in place for situations exactly like this one.

$\underline{\text { Self-Promotion }}$

3. Kelly could use this opportunity to boost her average for graduation.

6. Breaking school policy could threaten Kelly's graduation.

9. Kelly needs to forget about others and think about what is best for her.

13. If Kelly ends the relationship, James may be angry and purposely give her low grades.

$\underline{\text { Reading Check }}$

12. Kelly and James have not broken any rules 


\section{Scenario 2: Refugees with Health Problems}

Makayla is a government case worker and her job is to read immigration applications. After reading all files she must pass only those files that are approved for entry into her country to her boss. Civil wars have devastated parts of the world and thousands of people are leaving their homes, hoping to enter Makayla's country. Unfortunately many people are very ill and will require extended medical care. Makayla's government's policy is to accept healthy applicants first, but she knows that the sick applicants are in more dangerous situations. Makayla must decide whether or not to let in the healthy applicants first.

\section{$\underline{\text { Care }}$}

14. There are situations where following policy isn't the best choice.

17. Makayla should focus on giving help where it is needed most.

20. Showing compassion is more important than following the rules.

\section{$\underline{\text { Justice }}$}

15. Makayla should be objective when making her decisions.

18. It is important to always follow policy.

21. Makayla cannot let emotions cloud her judgment.

\section{Self-Promotion}

16. If Makayla does not follow her government's policy, she could be fired.

19. Makayla does not personally benefit from helping the sick applicants, so why bother?

23. Makayla will only get ahead in her career if she follows the rules.

\section{$\underline{\text { Reading Check }}$}

22. It is Makayla's job to use her judgment and do what she thinks is best. 


\section{Scenario 3: Drunk Driving}

Joe has been a police officer for 15 years in a large city. One night while working he notices a car driving outside its lane and think the driver may be drunk. He pulls the car over and asks the driver to complete a sobriety test. The driver fails the test but is very polite and apologetic. He admits that he does not usually drink, but was coming from a dinner where he had a few drinks. The driver tells Joe that driving is a large part of his job and if he receives a ticket he will be unable to work. The roads are empty at this late hour and the driver is a short 5 minute drive from his home. Joe must decide whether or not to arrest the driver.

$\underline{\text { Care }}$

24. Joe's primary concern is the driver's safety.

27. The driver's financial livelihood is at risk.

30. The late hour and empty roads make it less likely the driver will have an accident.

33. Innocent people could be hurt if the man drives home.

Justice

25. Driving while impaired is extremely dangerous.

28. Joe should treat the driver the same as any other offender.

31. There are no excuses for allowing someone to drive drunk.

34. Joe should be objective.

$\underline{\text { Self-Promotion }}$

26. Joe should not do anything that could jeopardize his own job.

29. It is not Joe's responsibility to clean up the mistakes of other people.

32. If Joe makes exceptions for people, he will never get ahead in his career.

36. If Joe does the driver a favour, he should get something in return.

$\underline{\text { Reading Check }}$

35. The driver is an alcoholic and needs help. 


\section{Scenario 4: Cheating}

Jordan and Dan are close friends and both work for the same company. Dan has been dating his girlfriend Alex for the past three years, and Jordan recently started dating Alex's friend, Jamie. The four have all become close friends and spend most of their time together. Dan recently told Jordan that he plans to propose to Alex.

One weekend Dan and Jordan are asked to attend a work conference out of town. Both make plans to attend the conference, but at the last minute Jordan cancels his trip. Early Saturday morning, Jordan walks to the local coffee shop. On his way he sees Alex coming out of an unfamiliar house. She is followed by a man holding her hand. Before Alex leaves, the man kisses her passionately. Jordan ducks into a nearby store to avoid being seen by Alex. Jordan must decide whether or not to tell Dan what he saw.

\section{$\underline{\text { Care }}$}

37. The most important thing is for Dan not to be hurt.

40. Jordan would not cause harm to someone else's relationship.

43. If Alex is cheating on Dan, their relationship must not be as happy as Jordan thought.

46. Jordan's decision will have an impact on all four friends.

\section{Justice}

38. Dan has a right to know that Alex is cheating.

41. Regardless of Alex's reasons, the rules of her relationship with Dan have been violated.

44. Alex should be held accountable for her actions.

48. Under no circumstances is it acceptable for someone to cheat in a relationship.

\section{$\underline{\text { Self-Promotion }}$}

39. Jordan could damage his own relationship with Jamie.

42. If Jordan tells Dan the truth, he may become angry at Jordan and choose to believe Alex instead.

45. Jordan could keep this information to himself and use it against Alex when it is most beneficial for him.

\section{$\underline{\text { Reading Check }}$}

47. Dan and Alex are not in a serious relationship. 


\section{Scenario 5: Assisted Suicide}

Susan is a doctor working in a large hospital. She has an elderly patient who has been fighting lung cancer for years. The patient has tried many treatments, but the cancer continues to return. Recently, the patient has decided to stop treatment and allow her disease to run its course. One night, while checking on the patient, she tells Susan that she is in a great deal of pain and is having difficulty breathing. She says that she would like to end her suffering by taking her own life, but she needs Susan's help. Susan must make a decision about whether or not to help.

$\underline{\text { Care }}$

49. It would greatly upset Susan to see her patient in pain.

52. Susan could threaten her relationships with her colleagues.

55. If their roles were reversed, Susan would hope her own doctor would consider her wishes.

58. In some cases, letting someone suffer is worse than helping them die.

Justice

50. Helping anyone commit suicide is morally wrong.

53. It is never okay to help someone end their life.

56. Susan has a responsibility to tell her boss of the patient's intentions.

59. The patient has the right to make her own decisions about her health care, within the limits of the law.

Self-Promotion

51. Susan could get into serious trouble.

57. The risk of being caught is too high.

61. This is not Susan's problem to solve.

$\underline{\text { Reading Check }}$

60. The patient's current treatment could cure her cancer. 


\section{Scenario 6: Plagiarism}

Mark is a student working at a news company. One day Mark hopes to be a journalist. Upset that he has worked for the company for a year and has not written anything, Mark decide to write a story on his own. He works on the story for weeks, until his are very proud of the final draft. Mark shows the article to his boss, Glen, who reads the article. Glen praises Mark on his work ethic, but he does not think the article is good enough to be on the website.

The next week Mark is reading the company's website, when he sees his article on the homepage. Mark is excited until he notices the first author is his supervisor Glen, while Mark is listed second. The editor congratulates Glen on his work. The editor tells Mark that if he stays with Glen he will learn everything he needs to know about the business. Mark must decide whether or not to confront Glen.

\section{$\underline{\text { Care }}$}

62. Mark could threaten his relationship with Glen.

65. Mark has a right to be hurt my Glen's actions, but he should also show respect for his superior.

68. Mark is a student and still learning from Glen.

71. Glen is the professional, and without him Mark would not have anything published.

$\underline{\text { Justice }}$

63. Regardless of the consequences, the editor should be made aware of the truth.

66. Plagiarism is a serious offence for a journalist and Glen should be punished.

69. Copying another person's work is never acceptable.

72. Under no circumstances is it acceptable to take credit for another person's work.

\section{Self-Promotion}

64. Mark wrote the article and deserves all the credit.

67. Mark will only get ahead in his career if he stands up for himself.

70. Mark should do what is best for his career in the long-term.

74. It is okay for Mark to do what is best for himself.

$\underline{\text { Reading Check }}$

73. Glen wrote the article too, so he has done nothing wrong. 
APPENDIX B

NMREB Ethics Approval

Western

Research Ethics Research

Use of Human Participants - Initial Ethics Approval Notice

\author{
Principal Invéstigator Pror. Tóny. Vernòn \\ File Number: 104555 \\ Review Level: Delegated \\ Protocol Title: The Development and Validation of a Multidimensional Measure of Morai Orientation \\ Department \& Institution: Social SciencelPsycheicsy. Western University. \\ Sponsor: The Pioneer Fund
}

Ethics. Approval Date: November 27; 2013 Expiny Dates. August 31, 2014

Documents Reviewed \& Approved \& Documents Received for tnformation:

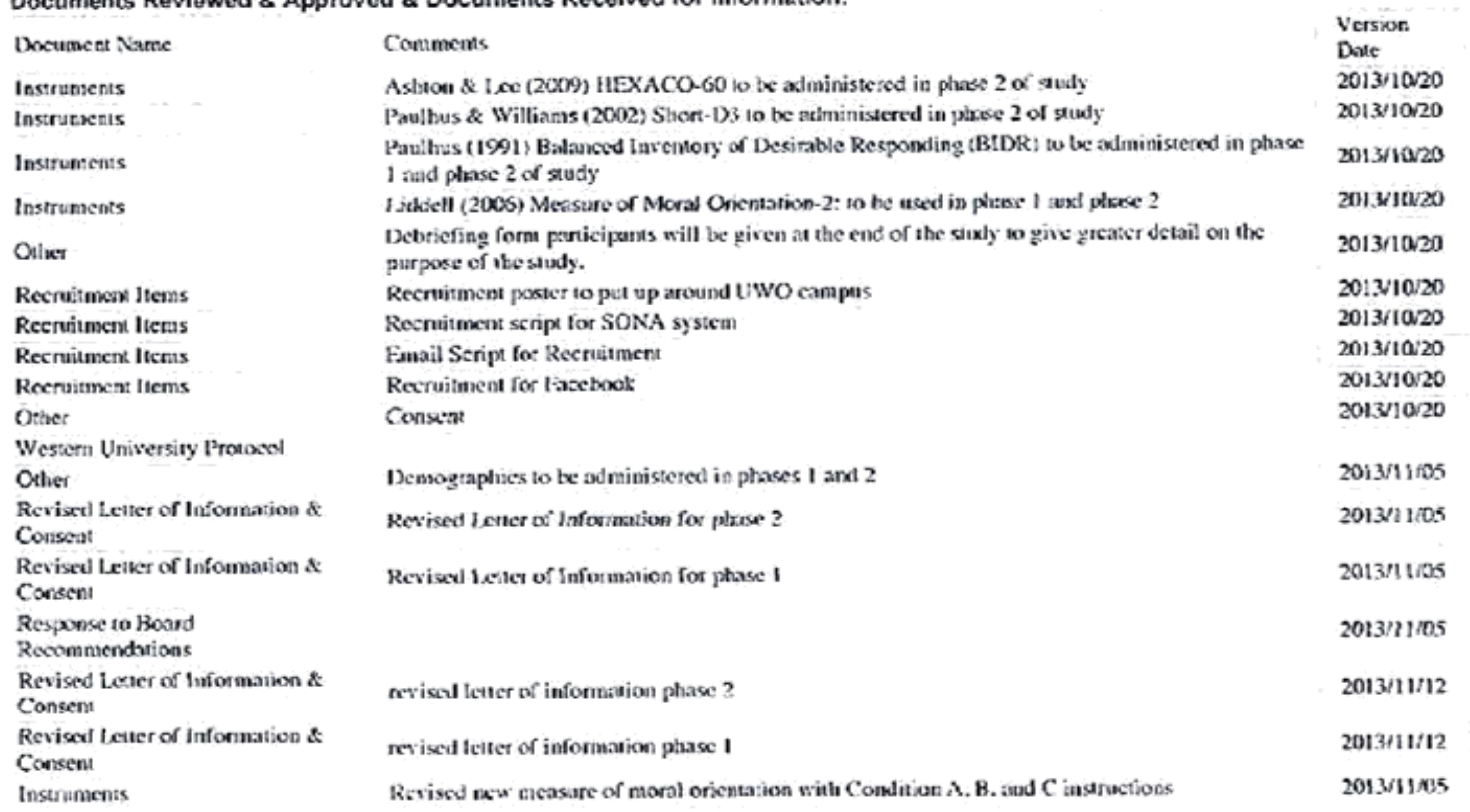

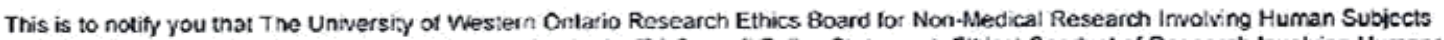
(NMREB) khich is crganized and operates according to the Tri Counci Pclicy Staternent Einiced Conduct of Research Imwolving Humans and the applicable laws and regu atons of Ontario has cramted approval to the above named researeh stuot on the approval odate noted. above.

This approval shall remain valid until the expry date noted ascive assuming tinely and acceptable responses to the NVREB's persodic requests for suiveilanse and monitoring information.

Members of the MMREB who are named as invcsticalors in research studes, or declare a conflict of interes: do not participate in discussions related to; nicr vote on; sisch studies when they are presented to the NMREB.

The Chair of the NMREB is Dr. Rley Hinson, The NMREB is registereo with the U.S. Department of Heath 8 . Human Services under the IRB registration rumber IRB 00000941. 


\section{APPENDIX C}

\section{Reduced Version of the AMO (Study 2)}

Instructions: Below are a number of factors that may come to mind when trying to make a decision. For each factor, please rate how likely it is to impact your final decision (regardless of what that decision is).

\section{Scenario 1: Student/Teacher Relationships}

You are out with your friends celebrating the end of summer and will soon be returning to school. While having a few drinks at a local bar, you are approached by an attractive individual. You begin talking and find you have an immediate connection. At the end of the night you exchange numbers and begin dating.

When your classes begin, you discover that your partner is the teacher for one of your classes. While you knew that they worked at your school, they were told they would be teaching a different class, but were switched last minute. It is against school policy for teachers and students to date. You must decide whether or not you will continue dating your teacher.

$\underline{\text { Care }}$

4. I would not want to hurt my partner.

10. I would feel guilty if my partner lost his/her job because of our relationship.

$\underline{\text { Justice }}$

2. My teacher has a responsibility to report his/her relationship with me to the school.

11. I think school policies are put in place for situations exactly like this one.

Self Promotion

9. I need to forget about others and think about what is best for me.

13. If I end the relationship, my partner may be angry and purposely give me low grades.

$\underline{\text { Reading Check }}$

12. We have not broken any rules. 


\section{Scenario 2: Refugees with Health Problems}

You are a government case worker and your job is to read immigration applications. After reading all files you must pass only those files that are approved for entry into your country to your boss. Civil wars have devastated parts of the world and thousands of people are leaving their homes, hoping to enter your country. Unfortunately many people are very ill and will require extended medical care. Your government's policy is to accept healthy applicants first, but you know that the sick applicants are in more dangerous situations. You must decide whether or not to let in the healthy applicants first.

$\underline{\text { Care }}$

17. I would focus on giving help where it is needed most.

20. Showing compassion is more important than following the rules.

$\underline{\text { Justice }}$

21. I cannot let emotions cloud my judgment.

\section{Self-Promotion}

19. I do not personally benefit from helping the sick applicants, so why bother?

23. I will only get ahead in my career if I follow the rules.

\section{Reading Check}

21. It is my job to use my judgment and do what I think is best.

\section{Scenario 3: Drunk Driving}

You have been a police officer for 15 years in a large city. One night while working you notice a car driving outside its lane and think the driver may be drunk. You pull the car over and see your uncle is the driver. You ask him to complete a sobriety test. Your uncle fails the test but is very polite and apologetic. You know that your uncle does not usually drink, and he admits to you that he is coming from a dinner where he had a few drinks. You know that driving is a large part of your uncle's job and if he receives a ticket he will be unable to work. The roads are empty at this late hour and your uncle is a short 5 minute drive from his home. You must decide whether or not to arrest your uncle.

\section{$\underline{\text { Care }}$}

24. My primary concern is my uncle's safety.

27. My uncle's financial livelihood is at risk.

$\underline{\text { Justice }}$

28. I should treat my uncle the same as any other offender.

31. There are no excuses for allowing someone to drive drunk.

\section{Self-Promotion}

29. It is not my responsibility to clean up the mistakes of other people.

32. If I make exceptions for people, I will never get ahead in my career.

Reading Check

35. My uncle is an alcoholic and needs help. 


\section{Scenario 4: Cheating}

You and your close friend Jessie both work for the same company. Jessie has been dating Alex for the past three years, and you recently started dating Alex's friend, Jamie. The four of you have all become close friends and spend most of your time together. Jessie recently told you that he/she plans to propose to Alex.

One weekend you and Jessie are asked to attend a work conference out of town. You both make plans to attend the conference, but at the last minute you must cancel your trip. Early Saturday morning, you walk to the local coffee shop. On your way you see Alex coming out of an unfamiliar house. Alex is followed someone holding their hand. Before Alex leaves, the person kisses Alex passionately. You duck into a nearby store to avoid being seen by Alex. You must decide whether or not to tell Jessie what you saw.

\section{Care}

37. The most important this is for Jessie not to be hurt.

46. My decision will have an impact on all four of us being friends.

$\underline{\text { Justice }}$

38. Jessie has a right to know that Alex is cheating.

41. Regardless of Alex's reasons, the rules of his/her relationship with Jessie have been violated.

48. Under no circumstances is it acceptable for someone to cheat in a relationship.

Self-Promotion

45. I could keep this information to myself and use it against Alex when it is most beneficial for me.

$\underline{\text { Reading Check }}$

47. Jessie and Alex are not in a serious relationship. 


\section{Scenario 5: Assisted Suicide}

Your grandmother has been fighting lung cancer for years. She has tried many treatments, but the cancer continues to return. Recently, she has decided to stop treatment and allow her disease to run its course. One night, while visiting your grandmother in the hospital, she tells you that she is in a great deal of pain and is having difficulty breathing. She says that she would like to end her suffering by taking her own life, but she needs your help. You need to make a decision about whether or not to help.

Care

55. If our roles were reversed, I would hope my grandmother would consider my wishes.

58. In some cases, letting someone suffer is worse than helping them die.

$\underline{\text { Justice }}$

50. I believe helping anyone commit suicide is morally wrong.

53. It is never okay to help someone end their life.

\section{$\underline{\text { Self-Promotion }}$}

54. My grandmother's death is certain, and I could use the inheritance money sooner rather than later.

61. This is not my problem to solve.

Reading Check

60. My grandmother's current treatment could cure her cancer.

\section{Scenario 6: Plagiarism}

You are a student working at a news company. One day you hope to be a journalist. Upset that you have worked for the company for a year and have not written anything, you decide to write a story on your own. You work on the story for weeks, until you are very proud of the final draft. You show the article to your boss, Glen, who reads the article. Glen praises you on your work ethic, but he does not think the article is good enough to be on the website.

The next week you are reading the company's website, when you see your article on the homepage. You are excited until you notice the first author is your supervisor Glen, while you are listed second. The editor congratulates Glen on his work. The editor tells you that if you stay with Glen you will learn everything you need to know about the business. You must decide whether or not to confront Glen.

$\underline{\text { Care }}$

62. I could threaten my relationship with Glen.

68. I am a student and still learning from Glen.

$\underline{\text { Justice }}$

63. Regardless of the consequences, the editor should be made aware of the truth.

66. Plagiarism is a serious offence for a journalist and Glen should be punished.

72. Under no circumstances is it acceptable to take credit for another person's work.

$\underline{\text { Reading Check }}$

73. Glen wrote the article too, so he has done nothing wrong. 


\section{CURRICULUM VITAE}

\section{Education}

2012-present MSc, The University of Western Ontario

- concentration: Personality and Measurement

- expected completion date: Summer 2014

2008-2012 B.A. Honours Specialization Psychology, The University of Western Ontario

\section{Awards}

2014

Joseph-Armand Bombardier Canada Graduate Scholarship Doctoral Award

- awarded by: Social Sciences and Humanities Research Council (SSHRC)

- value: $\$ 105,000$

2014 Ontario Graduate Scholarship (declined)

- awarded by: The Ontario Student Assistance Program

- value: $\$ 15,000$

$2013 \quad$ Graduate Student Teaching Award

- awarded by: Western University Graduate Student Teaching Assistants Award Committee

- value: $\$ 500+$ certificate of achievement

2013 Ontario Graduate Scholarship

- awarded by: The Ontario Student Assistance Program

- value: $\$ 15,000$

2012 Joseph-Armand Bombardier CGS Master's Scholarship

- awarded by: Social Sciences and Humanities Research Council (SSHRC)

- value: $\$ 17,500$

2012 Ontario Graduate Scholarship (declined)

- awarded by: The Ontario Student Assistance Program

- value: $\$ 15,000$

2012 The University of Western Ontario Gold Medal

- awarded by: The University of Western Ontario

- value: N/A (medal of achievement) 


\section{Publications}

Giammarco, E.A., \& Vernon, P.A. (2014). Vengeance and the Dark Triad: The role of empathy and perspective taking in trait forgivingness, Personality and Individual Differences, 67, 23-29.

Veselka, L., Giammarco, E.A., \& Vernon, P.A. (2014). The Dark Triad and the seven deadly sins, Personality and Individual Differences. 67, 75-80.

Giammarco, E.A., Atkinson, B., Veselka, L., Baughman, H.M., \& Vernon, P.A. (2013). The Relation between Antisocial Personality and the Perceived Ability to Deceive. Personality and Individual Differences, 54, 246-250.

Giammarco, E.A. (2013). Edgar Allan Poe: A psychological profile. Personality and Individual Differences, 54, 3-6.

Baughman, H.M., Giammarco, E.A., Veselka, L., Schermer, J.A., Martin, N.G., Lynskey, M., \& Vernon, P.A. (2012). A behavioral genetic study of humor styles in an Australian sample. Twin Research and Human Genetics, 15, 663-667.

Baughman, H.M., Martens, S., Giammarco, E.A., \& Vernon, P.A. (2012). Relationships between bullying behaviours and the dark triad: A study with adults. Personality and Individual Differences, 52, 571-575.

Giammarco, E.A. (2011). Someone else's twin: The true story of babies switched at birth. A Review. Personality and Individual Differences. doi: 10.1016/j.paid.2011.10.042

\section{Related Work Experience}

2013-present Research Associate, Sigma Assessment Systems

2011-2014 Research Assistant, The University of Western Ontario

2012-2014 Teaching Assistant, The University of Western Ontario 